\title{
Whisker Formation Induced by Component and Assembly Ionic Contamination
}

\author{
POLINA SNUGOVSKY, ${ }^{1,3}$ STEPHAN MESCHTER,${ }^{2}$ ZOHREH BAGHERI, ${ }^{1}$ \\ EVA KOSIBA, ${ }^{1}$ MARIANNE ROMANSKY,${ }^{1}$ and JEFFREY KENNEDY ${ }^{1}$
}

\begin{abstract}
1.-Celestica, 844 Don Mills Road, Toronto, ON M3C 1V7, Canada. 2.-BAE Systems, 600 Main
\end{abstract} Street, Johnson City, NY 13790, USA. 3.—e-mail: polina@celestica.com

\begin{abstract}
This paper describes the results of an intensive whisker formation study on $\mathrm{Pb}$-free assemblies with different levels of cleanliness. Thirteen types of as-received surface-mount and pin-through-hole components were cleaned and intentionally contaminated with solutions containing chloride, sulfate, bromide, and nitrate. Then the parts were assembled on double-sided boards that were also cleaned or intentionally contaminated with three fluxes having different halide contents. The assemblies were subjected to high-temperature/highhumidity testing $\left(85^{\circ} \mathrm{C} / 85 \% \mathrm{RH}\right)$. Periodic examination found that contamination triggered whisker formation on both exposed tin and solder fillets. Whisker occurrence and parameters depending on the type and level of contamination are discussed. Cross-sections were used to assess the metallurgical aspects of whisker formation and the microstructural changes occurring during corrosion.
\end{abstract}

Key words: Tin whiskers, ionic contamination, $\mathrm{Pb}$-free assembly, microstructure, high humidity

\section{INTRODUCTION}

Military, aerospace, and other high-reliability industries have experienced increased risks of system failure due to tin whiskers. The tin whisker problem has been the subject of intensive research over the past decade. Almost all of the research on tin whiskers has been concentrated on components $;{ }^{1-5}$ Sn plating composition and thickness, grain size, grain orientations, and $\mathrm{Ni}$ underlayer factors have been intensively studied, producing a great deal of knowledge. However, this approach does not consider the very real situation in which components are assembled on circuit boards using $\mathrm{Pb}$-free solder alloys and fluxes. Many important factors are not taken into consideration and have not been properly addressed yet, including questions such as: (1) Does the level of contamination of piece-parts and boards before assembly, and flux residue after assembly, affect whisker formation? (2) What cleanliness criteria and requirements for

(Received April 13, 2011; accepted October 28, 2011; published online November 19, 2011) assembly materials and parameters may reduce the risk of whisker formation? (3) Does external contamination exaggerate the risk of corrosion and whisker growth in harsh environments such as salt mist or sulfur-rich atmosphere?

In a previous study, ${ }^{6}$ the authors found that, in $\mathrm{Pb}$-free solder joints to Alloy 42 base material, leads can form long Sn whiskers under certain conditions. The tin whiskers grew from both bulk SAC405 (Sn-3.8Ag-0.7Cu) and SAC305 (Sn-3Ag-0.5Cu) solder due to the following factors: solder microstructure and its modification during oxidation and corrosion, Alloy 42 base material, base material underplating quality and contamination, overall piece-part contamination, and flux residue on solder. It is suspected that the origin of whiskering is related to corrosion. Corrosion was observed to have propagated through the eutectic regions in the interdendritic spaces of the solder and was accompanied by intensive diffusion in the bulk solder. The driving force for whisker nucleation and growth is suspected to involve local compressive stresses in solder regions with chemically modified microstructure and composition. These local zones are surrounded by 
nonmodified solder and are under high stress because its volume is changed. Highly stressed pure tin regions generally undergo stress relaxation via hillock and whisker formation.

Several recently published studies support an important role for fluxes and other sources of ionic contamination and reflow atmosphere in whisker growth from solder joints. ${ }^{7-11}$ However, there is still a lack of knowledge on component contamination before assembly, Sn plating integrity and other plating defects, assembly materials such as solder pastes and wave and rework fluxes, and assembly cleanliness.

This paper reports initial results from a joint Celestica/BAE Systems study on whisker formation and mitigation funded by the Strategic Environmental Research and Development Program (SERDP). The main goal of experiments of this study is to assess whisker propensity at high-temperature/highhumidity $\left(85^{\circ} \mathrm{C} / 85 \% \mathrm{RH}\right)$ condition for assemblies soldered with the SAC305 (Sn-3.0\%Ag-0.5\%Cu) no-clean process. The various levels of component contamination before assembly and the final assembly cleanliness including different types of flux residue are examined in connection with whisker formation. The whisker propensity of loose components with electroplated Sn and the same components after attachment to the boards using SAC305 solder is evaluated. The whisker propensity of different component types and leadframe materials Alloy 42, C194, C7025, and C151 is assessed. The work also aims to choose the contaminant that yields the best whisker propensity for long-term experiments to be performed in this SERDP project. The discussion is primarily focused on solder joint microstructure and its relationship with whisker formation.

\section{EXPERIMENTAL PROCEDURES}

\section{Test Vehicle, Components, and Assembly}

The test vehicle employed in this study is shown in Fig. 1. It is a double-sided printed circuit board (PCB), designed and produced by Practical Components Inc. with a 13-component kit. It incorporates a variety of components, both low- and high-standoff, pin-through-hole (PTH) connector, and discretes (Table I). The components are of three different $\mathrm{Cu}$ alloys and Alloy 42. The alloy compositions are presented in Table I. The dimensions of the boards are $63 \mathrm{~mm} \times 63 \mathrm{~mm}$. The surface finish is immersion $\mathrm{Ag}$ over $\mathrm{Cu}$.

Components were divided into three groups. The first group was used as received. The level of contamination was analyzed using ion chromatography (IC). The second group was cleaned to achieve cleanliness about 10 times below industrial acceptance levels.* The third group was intentionally contaminated to an above average ionic content level. The

*Foresite cleanliness limits using C3 localized extractions and ion chromatography.

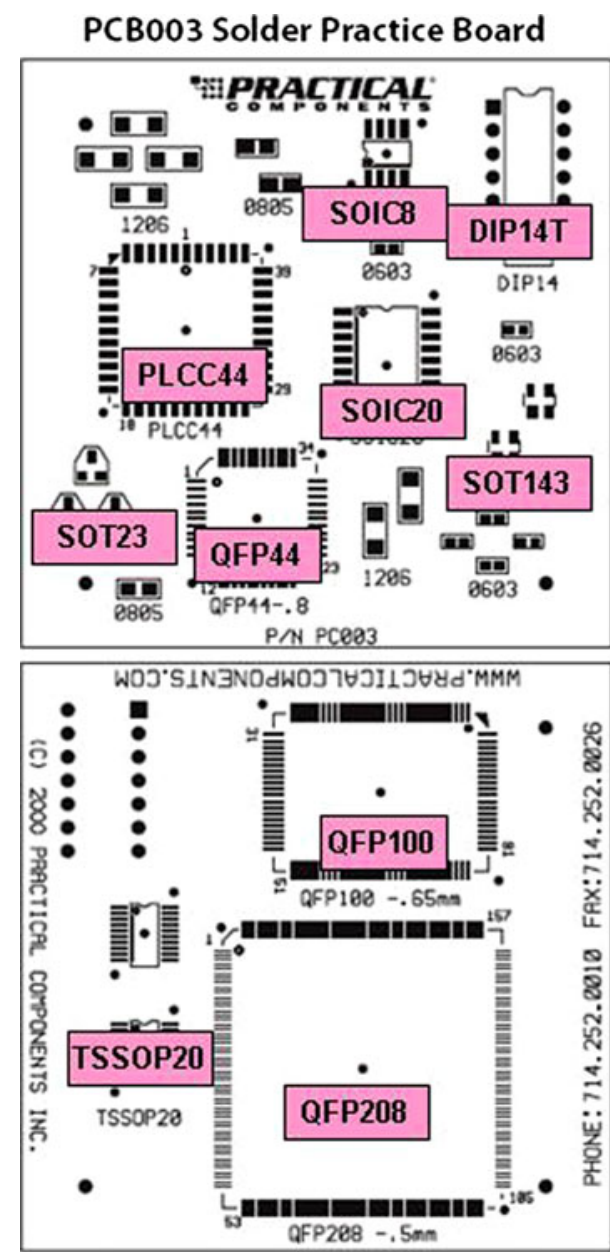

Fig. 1. Test vehicle: top picture, side A; bottom picture, side B.

cleaning and contamination methods are described below. To compare whisker formation on loose components and solder joints after assembly, samples from each of the three groups, of all 13 component types, were separated from the components used for assembly (Fig. 2). The rest of the components were assembled using $\mathrm{Sn}-3.0 \% \mathrm{Ag}-0.5 \% \mathrm{Cu}$ (SAC305) alloy and no-clean surface-mount assembly (SMT). The PTH connectors were manually attached using a solder fountain process. The schematic of the build matrix is shown in Fig. 3. After building, the assemblies were cleaned, left as is, or additionally contaminated (Fig. 3).

\section{Cleaning, Component Contamination, and Postassembly Contamination Methods}

\section{Cleaning}

Components and boards were placed into KPak bags with cleaning solution of $10 \%$ isopropanol (IPA)/90\% deionized water. The KPak bags were sealed and placed in a water bath at $80^{\circ} \mathrm{C}$ for $40 \mathrm{~min}$. After that the bags were removed from the water bath and placed on a vibration table for solution agitation for $40 \mathrm{~min}$. Parts were dried in a 
Table I. Component leadframe and surface finish materials

\begin{tabular}{|c|c|c|c|c|}
\hline $\begin{array}{l}\text { Package } \\
\text { Type }\end{array}$ & Part Description & $\begin{array}{l}\text { Lead Finish } \\
\text { Plating }\end{array}$ & $\begin{array}{l}\text { Leadframe } \\
\text { Substrate }\end{array}$ & Leadframe Alloy \\
\hline QFP & A-QFP208-28mm-.5mm-2.6-DC-Sn & Matte Sn & C7025 & $\mathrm{Cu}-(2.2-4.2) \mathrm{Ni}-(0.25-1.2) \mathrm{Si}-(0.05-0.3) \mathrm{Mg}$ \\
\hline QFP & A-QFP44-10mm-.8-3.2-DC-Sn & Matte Sn & $\mathrm{C} 7025$ & $\mathrm{Cu}-(2.2-4.2) \mathrm{Ni}-(0.25-1.2) \mathrm{Si}-(0.05-0.3) \mathrm{Mg}$ \\
\hline QFP & A-QFP100-14x20-.65-3.9-LF-DC-T & Matte Sn & $\mathrm{C} 7025$ & $\mathrm{Cu}-(2.2-4.2) \mathrm{Ni}-(0.25-1.2) \mathrm{Si}-(0.05-0.3) \mathrm{Mg}$ \\
\hline PDIP & A-PDIP14T-300mil-DC-Sn & Matte Sn & C194 & $\mathrm{Cu}-(2.1-2.6) \mathrm{Fe}-(0.015-0.15) \mathrm{P}-(0.05-0.2) \mathrm{Zn}$ \\
\hline PLCC & A-PLCC44T-DC-Sn & Matte Sn & C151 & $\mathrm{Cu}-0.1 \mathrm{Zr}$ \\
\hline SO & A-SO8GT-3.8mm-DC-Sn & Matte Sn & C194 & $\mathrm{Cu}-(2.1-2.6) \mathrm{Fe}-(0.015-0.15) \mathrm{P}-(0.05-0.2) \mathrm{Zn}$ \\
\hline SO & SO20GTR-7.6mm-Sn & Matte Sn & C194 & $\mathrm{Cu}-(2.1-2.6) \mathrm{Fe}-(0.015-0.15) \mathrm{P}-(0.05-0.2) \mathrm{Zn}$ \\
\hline SOT & SOT23-TR-Sn & Matte Sn & Alloy 42 & $\mathrm{Fe}-(39-41) \mathrm{Ni}-0.6 \mathrm{Mn}-0.05 \mathrm{Cr}-0.02 \mathrm{Si}-0.05 \mathrm{C}$ \\
\hline SOT & SOT143-TR-Sn & Matte Sn & C194 & $\mathrm{Cu}-(2.1-2.6) \mathrm{Fe}-(0.015-0.15) \mathrm{P}-(0.05-0.2) \mathrm{Zn}$ \\
\hline TSSOP & A-TSSOP20T-4.4mm-Sn & Matte Sn & $\mathrm{C} 7025$ & $\mathrm{Sn}-(2.2-4.2) \mathrm{Ni}-(0.25-1.2) \mathrm{Si}-(0.05-0.3) \mathrm{Mg}$ \\
\hline Discrete & 0805SMR-PA-5K-Sn-0 & Matte Sn & None & Ceramic \\
\hline Discrete & 1206SMR-PA-5K-Sn-0 & Matte Sn & None & Ceramic \\
\hline Discrete & 0603SMR-PA-5K-Sn-0 & Matte Sn & None & Ceramic \\
\hline
\end{tabular}

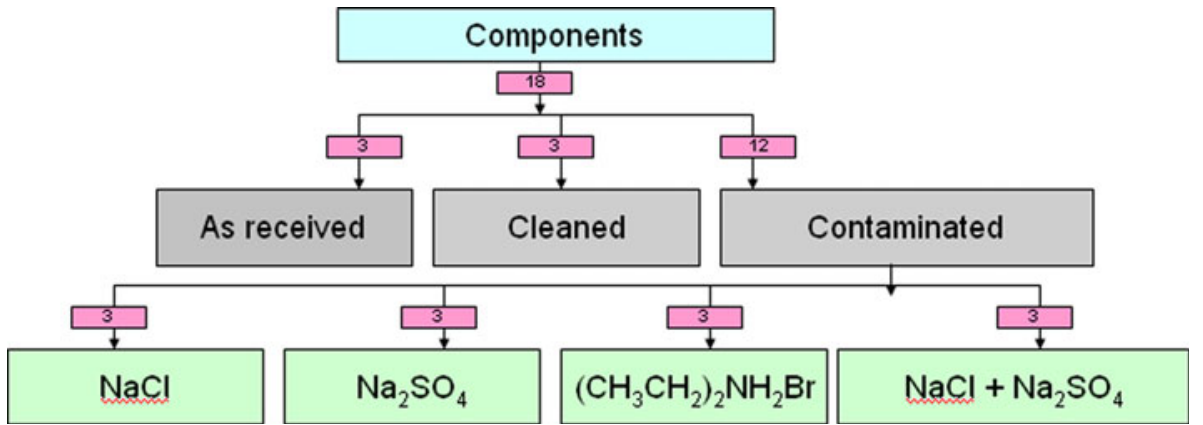

Fig. 2. Loose components, contamination schematic.

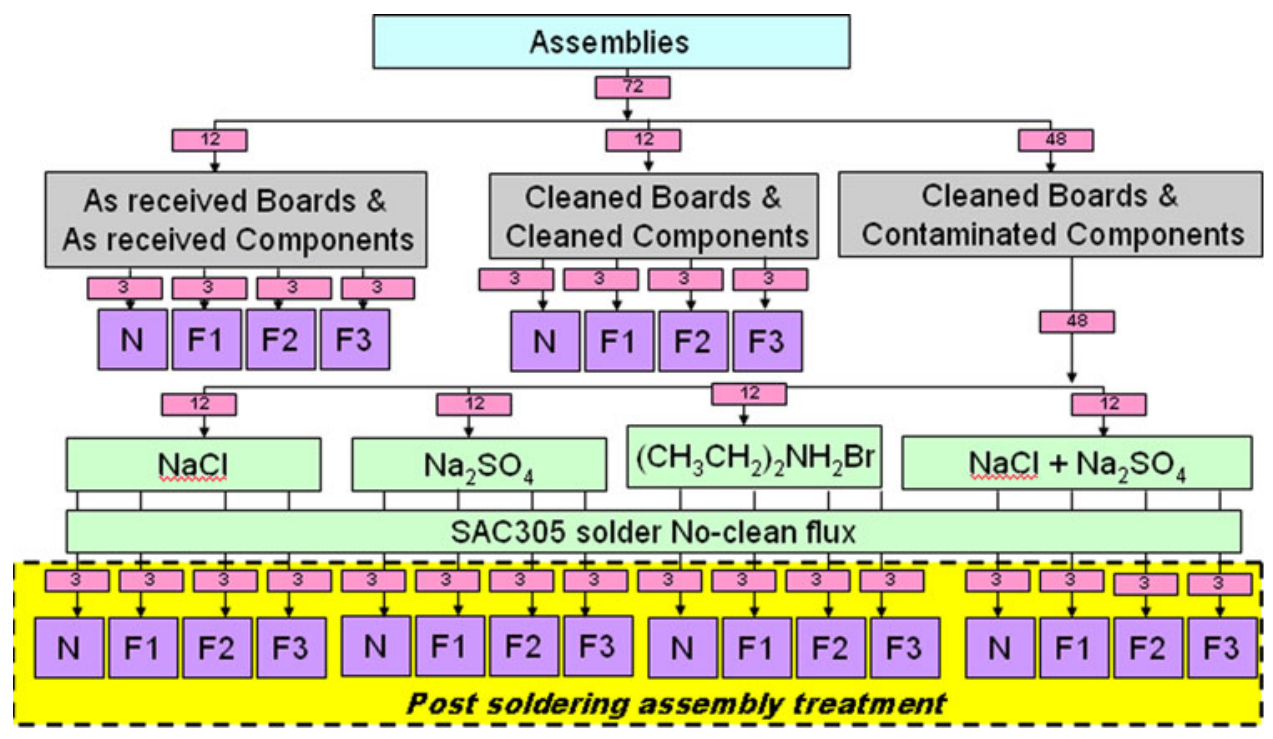

Fig. 3. Assembly and postassembly contamination schematic.

oven at $60^{\circ} \mathrm{C}$ for $10 \mathrm{~min}$. The process was repeated for a total of two wash cycles. IC was performed on each type of component; the typical level of contamination was 10 times below acceptable level (or $0.009 \mu \mathrm{g} / \mathrm{cm}^{2}$ to $0.017 \mu \mathrm{g} / \mathrm{cm}^{2} \mathrm{Cl}^{-}$and $0.069 \mu \mathrm{g} / \mathrm{cm}^{2}$ to $0.17 \mu \mathrm{g} / \mathrm{cm}^{2}$ total inorganic).

\section{Component Contamination}

The basis for the method used was Atotech's study ${ }^{11}$ that showed accelerated whisker growth on Sn-plated components contaminated with $2 \mathrm{mM}$ $\mathrm{NaCl}$ and $2 \mathrm{mM} \mathrm{Na}_{2} \mathrm{SO}_{4}$. In this study, the level of 
contamination was increased to $2.844 \mathrm{mM}$ to obtain a component contamination level above industry acceptance (see footnote 1 ). ${ }^{12}$ To examine how $\mathrm{NaCl}$ and $\mathrm{Na}_{2} \mathrm{SO}_{4}$ work together and double the overall level of contamination, a mixture of $2 \mathrm{mM} \mathrm{NaCl}$ and $2 \mathrm{mM} \mathrm{Na}_{2} \mathrm{SO}_{4}$ was used. $\left(\mathrm{CH}_{3} \mathrm{CH}_{2}\right)_{2} \mathrm{NH}_{2} \mathrm{Br}$ flux (2 wt.\%) was chosen as a fourth contaminant based on the results of Japan Electronics and Information Technology Industries Association (JEITA) work on creating whiskers. $^{13}$

Contamination solutions [166 ppm NaCl in DI water, $404 \mathrm{ppm} \mathrm{Na}_{2} \mathrm{SO}_{4}$ in DI water, $166 \mathrm{ppm}$ $\mathrm{NaCl}+404$ ppm $\mathrm{Na}_{2} \mathrm{SO}_{4}$ in DI water, and 2 wt.\% $\left(\mathrm{CH}_{3} \mathrm{CH}_{2}\right)_{2} \mathrm{NH}_{2} \mathrm{Br}$ in $25 \%$ rosin $+75 \%$ IPA] were placed in bath until it reached $35^{\circ} \mathrm{C}$. Then components were placed into jars containing contamination solutions. The jar was agitated and placed in bath for $4 \mathrm{~min}$. The solution and components were poured onto a stainless-steel mesh. The remaining components were placed in an oven to dry at $60^{\circ} \mathrm{C}$ for $10 \mathrm{~min}$. After that components were transferred to a clean tray. The parts were stored in a nitrogen chamber.

\section{Assembly Contamination Method}

Three fluxes widely employed in high-reliability electronics were using to imitate rework or handattachment situations when flux may flood under components and through vias to the bottom side of the board, may not be properly activated, and the flux residue cannot be fully removed. The fluxes were low-rosin halide-free (ROL0), rosin based with halide content below $0.05 \%$ (ROL1), and organic water soluble with halide content below $2.0 \%$ (ORH1) (the acronyms ROL0, ROL1, and ORH1 are flux designators according to the IPC JSTD 004 standard). The ORH1 flux was diluted $20 \times$ with DI water to imitate flux residue after cleaning. Syringes were used to measure a specified volume of flux for each component. Flux was slowly dispensed along the tips and tops of the leads and was allowed to dry. The flux compositions and the level of solder joint contamination are presented in Tables II and III, respectively.

All components were baked at $125^{\circ} \mathrm{C}$ for $4 \mathrm{~h}$ before assembly.

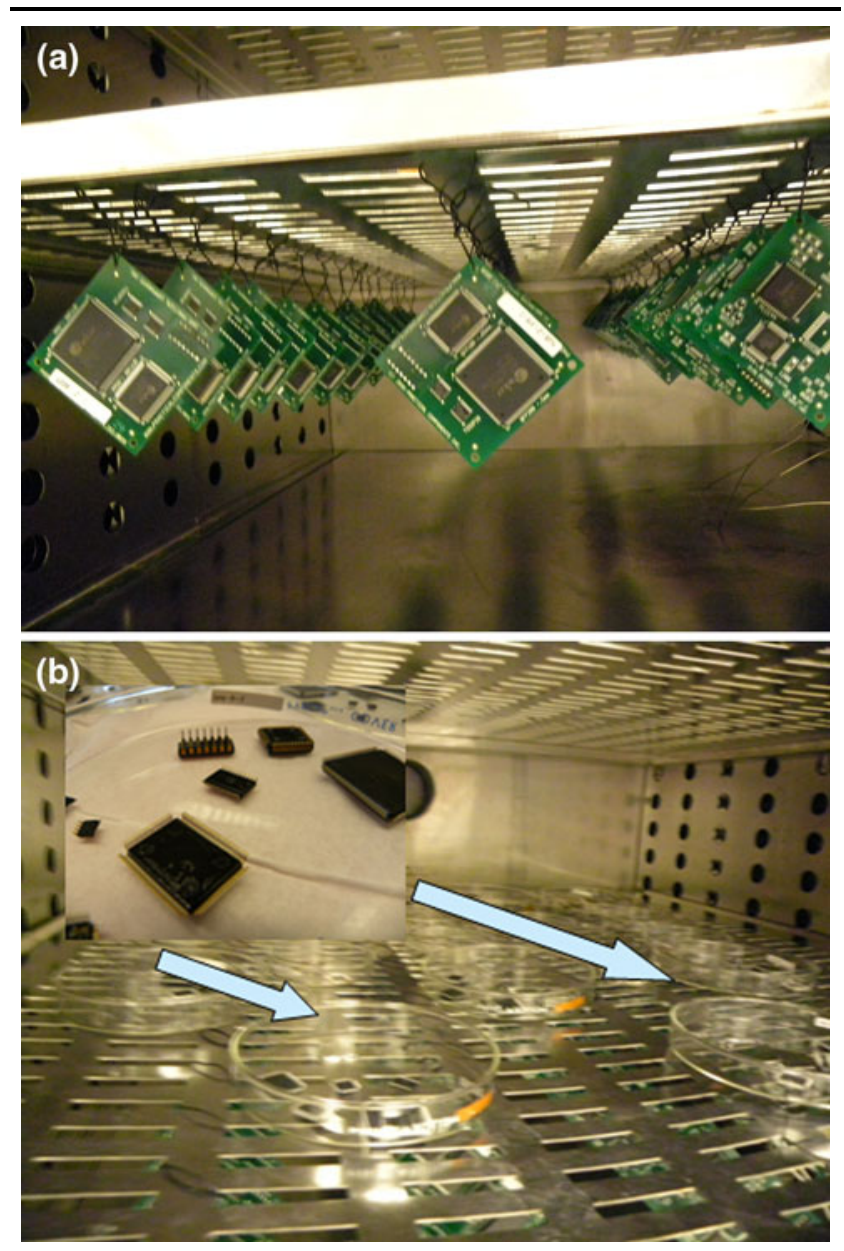

Fig. 4. Placement of (a) test vehicle and (b) loose components in the environmental chamber.

Table II. Flux composition

\begin{tabular}{lcccc}
\hline Flux & Adipate (\%) & & Chloride (\%) & Bromide (\%) \\
\cline { 2 - 2 } ORH1, water soluble & - & 3.5 & - \\
ROL1, rosin-based & - & - & 0.1 & \\
ROL0, low-rosin halide-free & 2.3 & 0.0032 & 0.0083 \\
\hline
\end{tabular}

Table III. Flux contamination on solder joints

\begin{tabular}{|c|c|c|c|}
\hline Flux & Adipate $\left(\mu \mathrm{g} / \mathrm{cm}^{2}\right)$ & Chloride $\left(\mu \mathrm{g} / \mathrm{cm}^{2}\right)$ & Bromide $\left(\mu \mathrm{g} / \mathrm{cm}^{2}\right)$ \\
\hline ORH1, water soluble diluted $20 \times$ with DI water & - & $4.65-10.86$ & - \\
\hline ROL1, rosin-based & - & - & $4.65-10.86$ \\
\hline ROL0, low-rosin halide-free & 186 & 0.31 & 0.78 \\
\hline
\end{tabular}



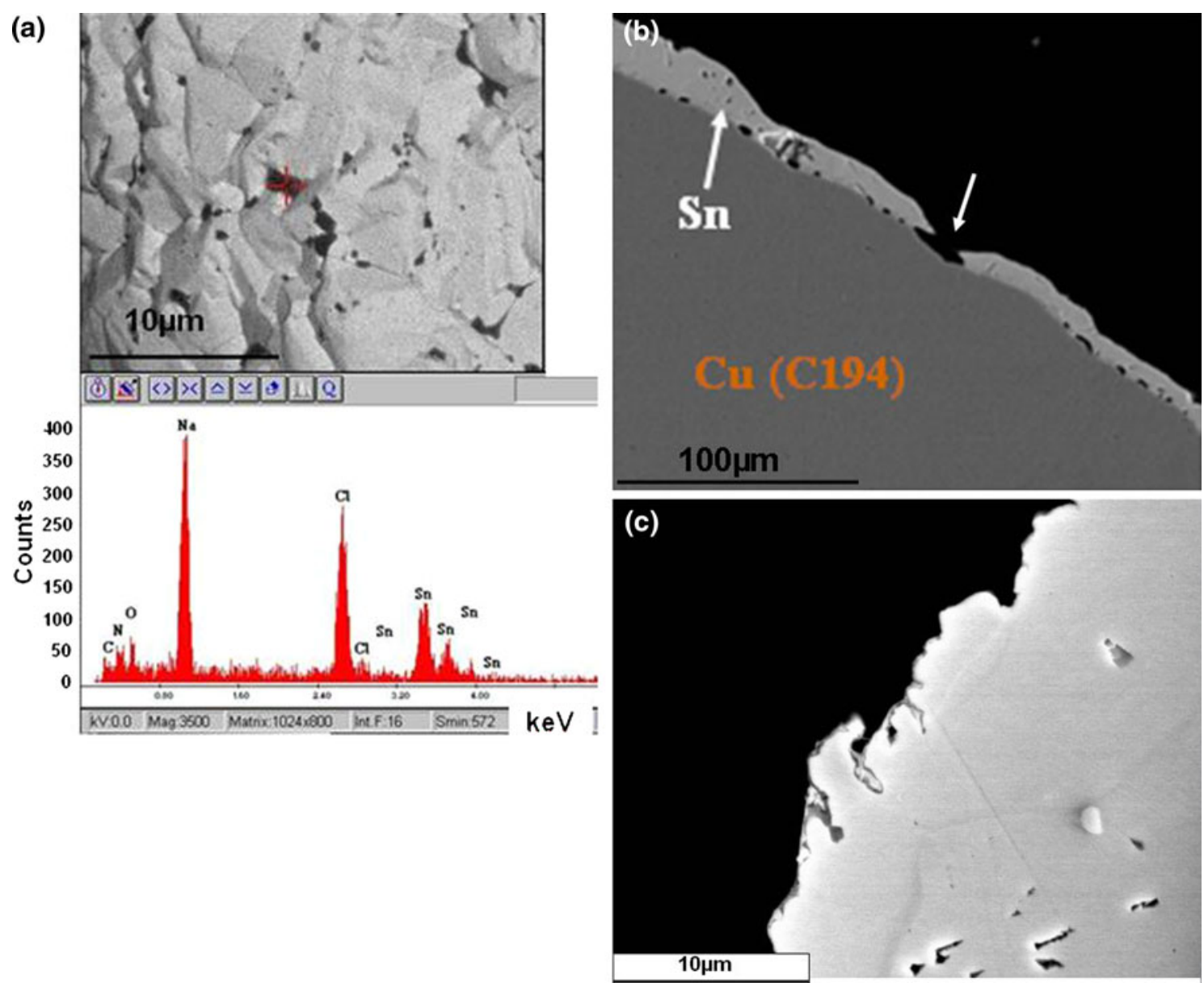

Fig. 5. Main areas of contamination segregations: (a) grain boundaries, (b) defects in plating (open voids and cracks), and (c) surface roughness grooves.

\section{Testing at $85^{\circ} \mathrm{C} / 85 \% \mathrm{RH}$ and Whisker Analysis}

The environmental whisker growth test was done per JEDEC JESD22-A121A standard. The parameters $\left[85^{\circ} \mathrm{C}\right.$ and $85 \%$ relative humidity $\left.(\mathrm{RH})\right]$ were chosen based on the data of the JEITA project ${ }^{13}$ that demonstrated whisker formation on contaminated coupons after $500 \mathrm{~h}$, which is faster than after lower-temperature treatment. Nihon Superior ${ }^{10}$ reported much longer whisker formation on solder at $85^{\circ} \mathrm{C} / 85 \% \mathrm{RH}$ compared with $40^{\circ} \mathrm{C} / 60 \% \mathrm{RH}$ and $60^{\circ} \mathrm{C} / 90 \% \mathrm{RH}$. Loose components (13 types $\times 18$ cleanliness variations $\times 3$ component per point $=702$ components) and assembled boards (72 cleanliness variations $\times 3$ per point $=216$ boards) were placed into the chamber as shown in Fig. 4. The chamber was set up to reach $85^{\circ} \mathrm{C} / 85 \% \mathrm{RH}$ in $4 \mathrm{~h}$. Then, samples were subjected to $500 \mathrm{~h}$ exposure. After the exposure, the chamber was slowly brought down to room temperature and humidity. The process was established to prevent water droplet formation. The samples were removed from the chamber and placed into the nitrogen chamber for 2 weeks for whisker analysis. Several boards and components were cross-sectioned for microstructure analysis. After whisker inspection, the vast majority of loose components and boards were returned to the high-temperature/high-humidity chamber for a second round of testing. The time of the second testing was two times longer than the first one, i.e., $1000 \mathrm{~h}$. The reason for this time increase is discussed later in this paper. The final whisker inspection was performed after $1500 \mathrm{~h}$ $(500 \mathrm{~h}+1000 \mathrm{~h})$.

Whisker inspection was predominantly carried out using scanning electron microscopy (SEM). The size of the board was suitable for placement into a variable-pressure Hitachi S-3000N microscope chamber. Loose components were placed with leads upward, in "dead bug" position. If whiskers were detected in the first of three boards, the remaining two were checked using optical microscopy to ensure the boards were identical to the first one and also contained whiskers. All three boards were analyzed using SEM if no whiskers were found in the first or second boards. Optical microscopy was also used for samples contaminated with 2 wt.\% $\left(\mathrm{CH}_{3} \mathrm{CH}_{2}\right)_{2} \mathrm{NH}_{2} \mathrm{Br}$ and ROL1 (rosin-based) flux after $500 \mathrm{~h}$ at $85^{\circ} / 85 \% \mathrm{RH}$ because of extreme charging 

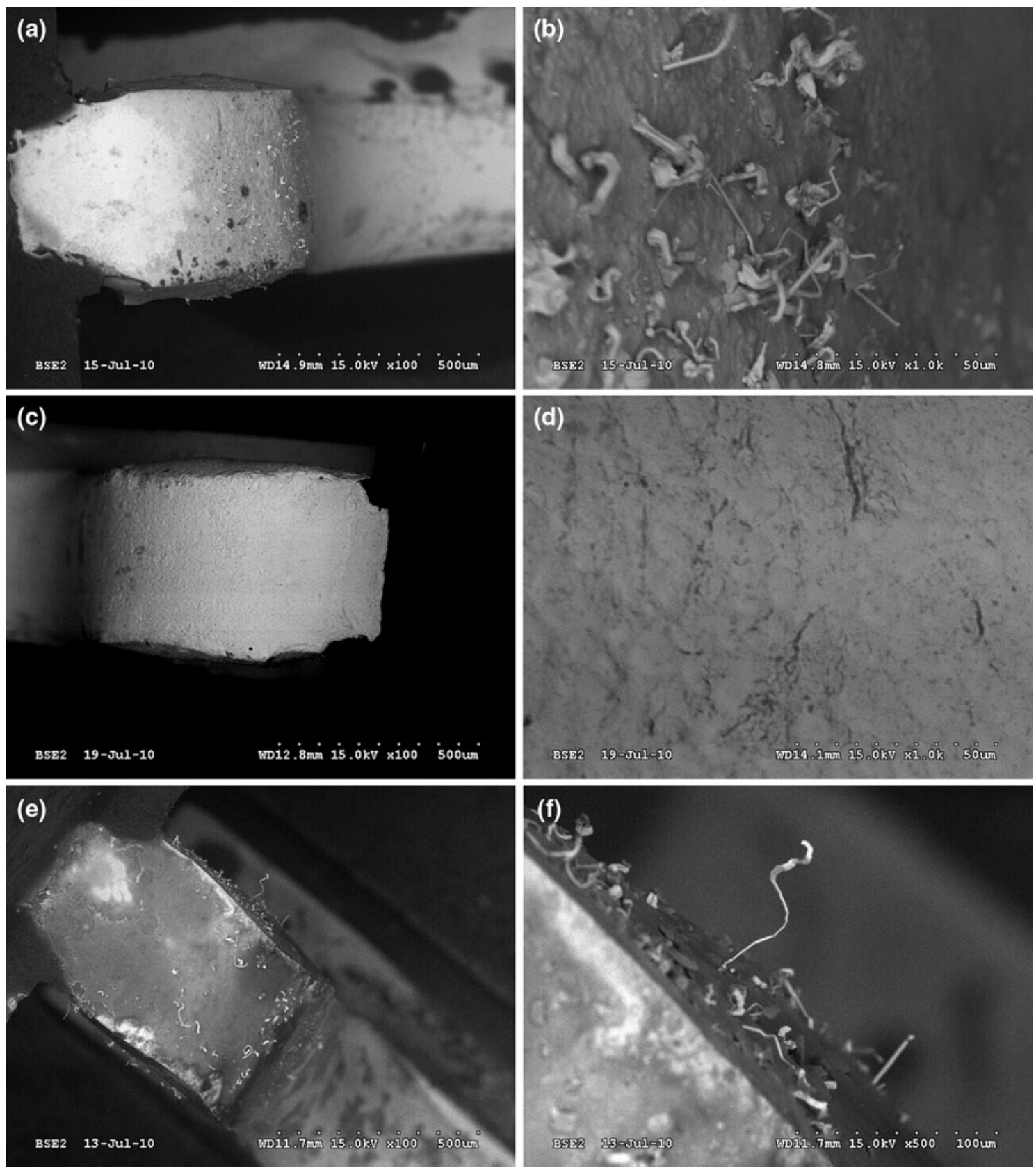

Fig. 6. Micrographs of SOIC20 after $500 \mathrm{~h}$ at $85^{\circ} \mathrm{C} / 85 \% \mathrm{RH}$ showing no whiskers when using components cleaned prior to assembly and with postassembly cleaning procedure $(a, b)$, short whiskers in as-received assemblies (c, d), and longer whiskers in contaminated assemblies (e, f).

and as a precaution against possible damage of flux residue in SEM. The final inspection after $1500 \mathrm{~h}$ exposure was carried out using scanning electron microscopy.

Images were taken at $40 \times$ and $90 \times$ using an optical stereoscope and at $100 \times, 500 \times$, and $1000 \times$ using SEM at typical locations and at the locations with the longest whiskers for the sample. To show whisker details, 2000× and higher magnification was used. The whisker length, diameter, density, and distribution were measured. The real magnification is indicated on each image by a micron bar.

\section{Metallurgical Examination}

To examine contamination levels and distributions, as-received, cleaned, and contaminated components were analyzed using IC, SEM (SEM; Hitachi S-4500 and SEM Hitachi S-3000N), and energy-dispersive x-ray spectroscopy (EDX; Oxford EDX). Loose components and assemblies were crosssectioned before and after high-temperature/highhumidity exposure to analyze Sn plating quality, solder coverage and microstructure, intermetallic thickness, oxidation, and corrosion product morphology and distribution. 


\section{RESULTS AND DISCUSSION}

\section{Component Contamination and Plating Quality}

Two samples per each of 13 as-received components were analyzed for cation and anion level using IC. Some components were contaminated above acceptable levels. Foresite-recommended levels for typical ionic residue species (see footnote 1) and Celestica customers' requirements for total inorganic ions were used as criteria. For instance, after $40 \mathrm{~min}$ extraction at $80^{\circ} \mathrm{C}$, the levels of chloride on PDIP14T $\left(0.50 \mu \mathrm{g} / \mathrm{cm}^{2}\right)$ and sulfate on QFP44 $\left(1.61 \mu \mathrm{g} / \mathrm{cm}^{2}\right)$ exceeded the Foresite requirements by $3.2 \times$ and $3.5 \times$, respectively. The cation content was also much higher in these samples, with sodium being more than $3 \times$ the level in the Foresite recommended table. Considering the total level of anions and cations, PDIP14T and QFP44 were $2.2 \times$ more contaminated than Celestica customers' requirements: $3.69 \mu \mathrm{g} / \mathrm{cm}^{2}$,

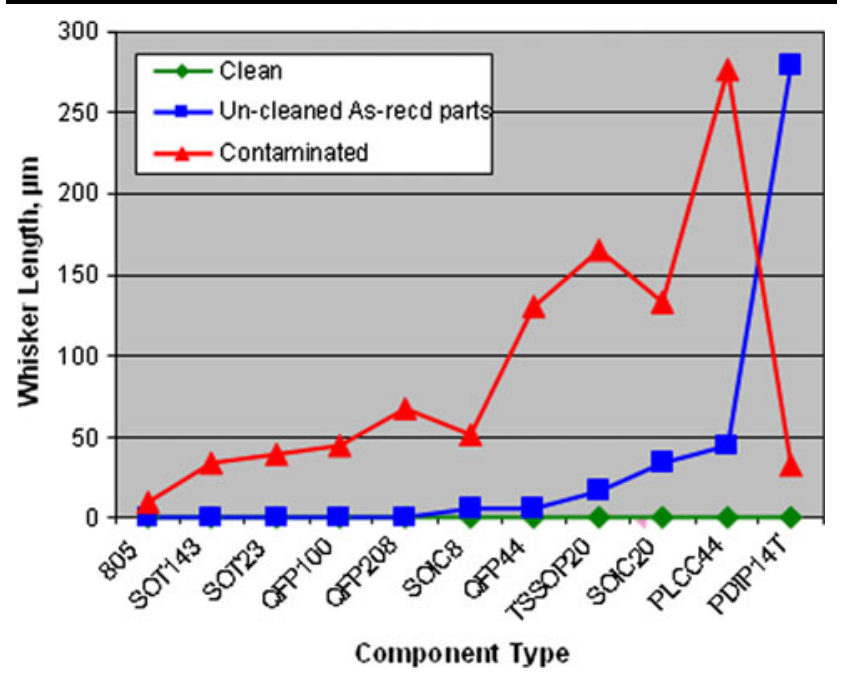

Fig. 7. Maximum whisker lengths after $500 \mathrm{~h}$ at $85^{\circ} \mathrm{C} / 85 \% \mathrm{RH}$ depending on assembly cleanliness.
$3.41 \mu \mathrm{g} / \mathrm{cm}^{2}$, and $1.74 \mu \mathrm{g} / \mathrm{cm}^{2}$, respectively. The level of contamination of as-received components is comparable to the component contamination level in production assemblies with long whiskers from prior work. ${ }^{6}$ Some of the as-received components were close to the industry accepted contamination limit of $1.67 \mu \mathrm{g} / \mathrm{cm}^{2}$.
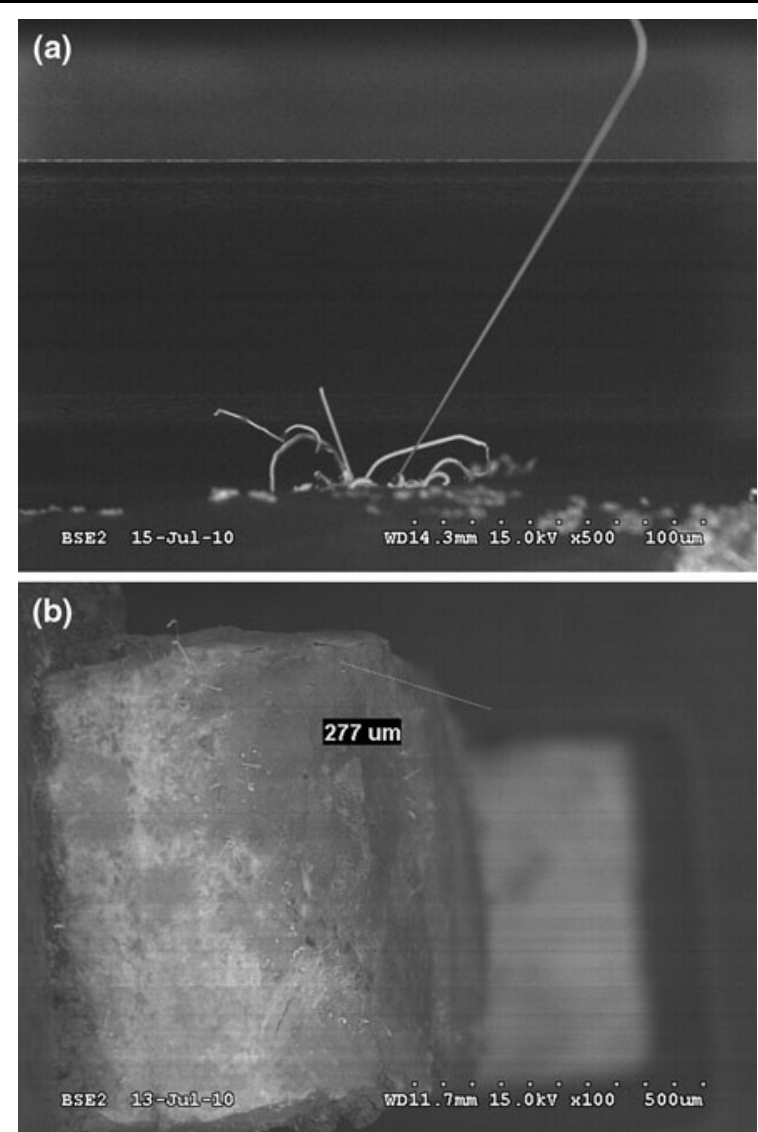

Fig. 8. Micrographs of PIDP14T (a) and PLCC44 (b) after $500 \mathrm{~h}$ at $85^{\circ} \mathrm{C} / 85 \% \mathrm{RH}$ with $280-\mu \mathrm{m}$ and $277-\mu \mathrm{m}$ whiskers, respectively.

Table IV. Relationship between level of contamination of as-received components and whisker formation

\begin{tabular}{|c|c|c|c|c|}
\hline $\begin{array}{l}\text { Sample } \\
\text { ID }\end{array}$ & $\begin{array}{l}\text { Total Inorganic } \\
\text { Anions }\left(\mu \mathrm{g} / \mathbf{c m}^{2}\right)\end{array}$ & $\begin{array}{l}\text { Total Inorganic } \\
\text { Cations }\left(\mu \mathrm{g} / \mathrm{cm}^{2}\right)\end{array}$ & $\begin{array}{l}\text { Total Inorganic } \\
\text { Ions }\left(\mu \mathrm{g} / \mathrm{cm}^{2}\right)\end{array}$ & $\begin{array}{c}\text { Whisker After } 500 \mathrm{~h} \\
\mathbf{8 5}^{\circ} \mathbf{C} / \mathbf{8 5} \% \mathrm{RH}\end{array}$ \\
\hline QFP208 & $\mathbf{0 . 9 5}\left(0.54 \mathrm{Cl}^{-}\right)$ & 0.40 & 1.35 & Yes (hillocks) \\
\hline QFP44 & $1.81\left(1.61 \mathrm{SO}_{4}^{2-}\right)$ & $1.86\left(0.29 \mathrm{Na}^{+}\right)$ & 3.69 & Yes (whiskers) \\
\hline QFP100 & $1.55\left(1.27 \mathrm{NO}^{3-}\right)$ & $1.88\left(0.51 \mathrm{Na}^{+}\right)$ & 3.22 & Yes (hillocks) \\
\hline PLCC & 0.23 & $1.27\left(0.68 \mathrm{Na}^{+}\right)$ & 1.50 & Yes (whiskers) \\
\hline SOIC8 & $\mathbf{3 . 6 1}\left(3.55 \mathrm{NO}^{3-}\right)$ & 0.70 & 4.31 & Yes (whiskers) \\
\hline SOIC20 & 0.36 & $1.32\left(0.68 \mathrm{Na}^{+}\right)$ & 1.67 & Yes (whiskers) \\
\hline SOT23 & 0.53 & 0.31 & 0.84 & No \\
\hline SOT143 & 0.29 & 0.65 & 0.95 & No \\
\hline TSSOP20 & 0.26 & 0.25 & 0.51 & No \\
\hline 0603 & 0.36 & $1.58\left(0.53 \mathrm{Na}^{+}\right)$ & 1.95 & No \\
\hline 0805 & 0.70 & 0.28 & 0.96 & No \\
\hline 1206 & 0.14 & 1.16 & 1.32 & No \\
\hline PDIP14 & $1.38\left(0.50 \mathrm{Cl}^{-} ; 0.39 \mathrm{SO}_{4}^{2-}\right)$ & $2.09\left(0.85 \mathrm{Na}^{+}\right)$ & 3.63 & Yes (whiskers) \\
\hline
\end{tabular}


(a)

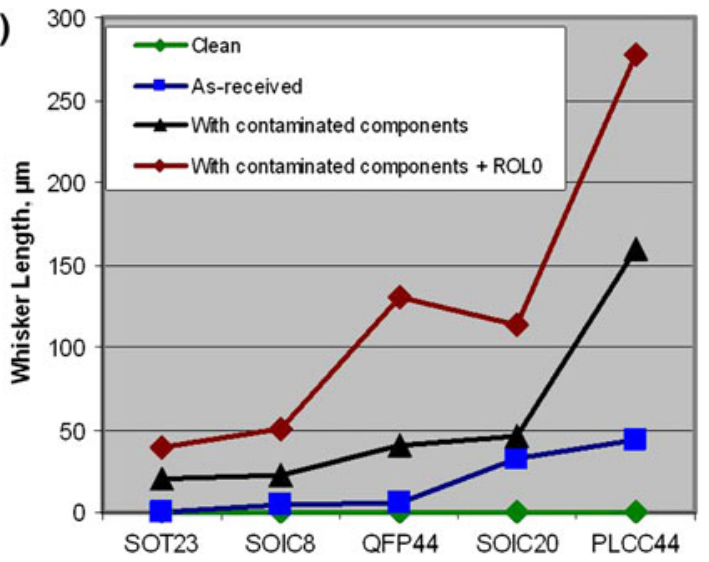

(b)

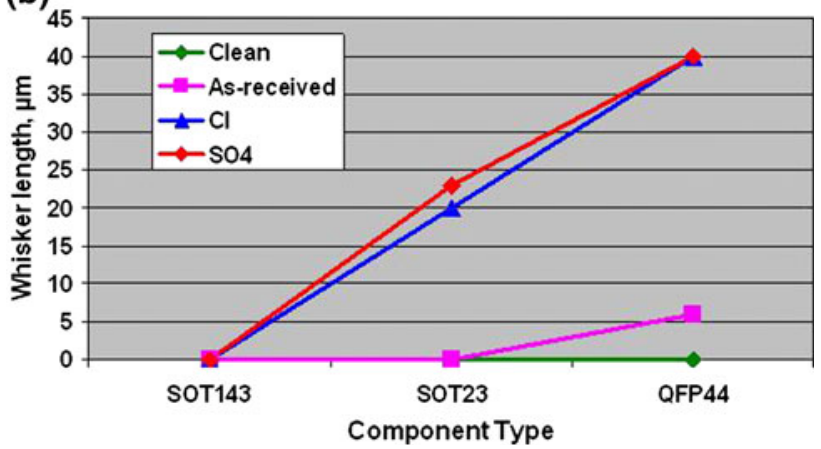

Fig. 9. Maximum whisker lengths after $500 \mathrm{~h}$ at $85^{\circ} \mathrm{C} / 85 \% \mathrm{RH}$ depending on assembly cleanliness, allowing separation of the effect of component contamination and flux residues on whisker formation (a), and showing no significant difference in whisker length depending on component contamination type (b).

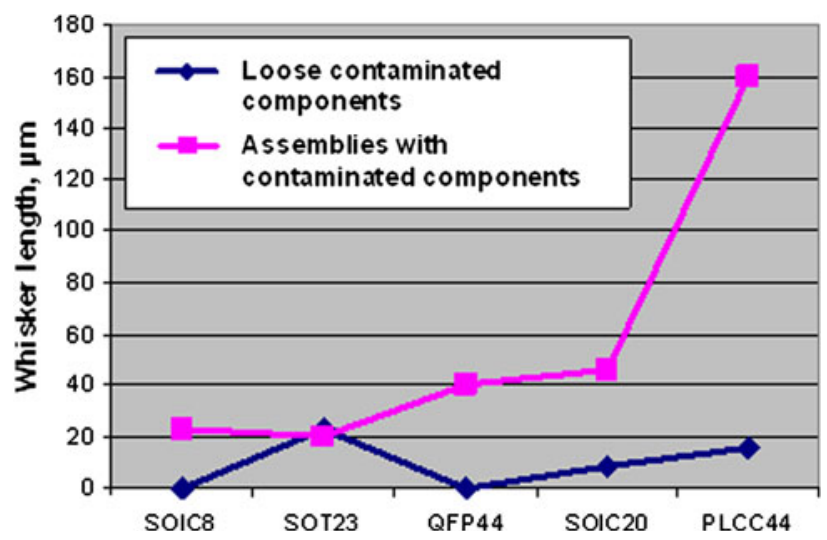

Fig. 10. Comparison of whisker length for loose and assembled components after $500 \mathrm{~h}$ at $85^{\circ} \mathrm{C} / 85 \% \mathrm{RH}$.

The components after cleaning had a typical level of contamination 10 times below the acceptable level (or $0.009 \mu \mathrm{g} / \mathrm{cm}^{2}$ to $0.017 \mu \mathrm{g} / \mathrm{cm}^{2} \mathrm{Cl}^{-}$and $0.069 \mu \mathrm{g} /$ $\mathrm{cm}^{2}$ to $0.17 \mu \mathrm{g} / \mathrm{cm}^{2}$ total inorganic).

The ionic level of the intentionally contaminated leaded components exceeded the level of as-received components and was above industry recommendations by factors of 2.9 to 5.3. This level was comparable to or even below the level of contamination of

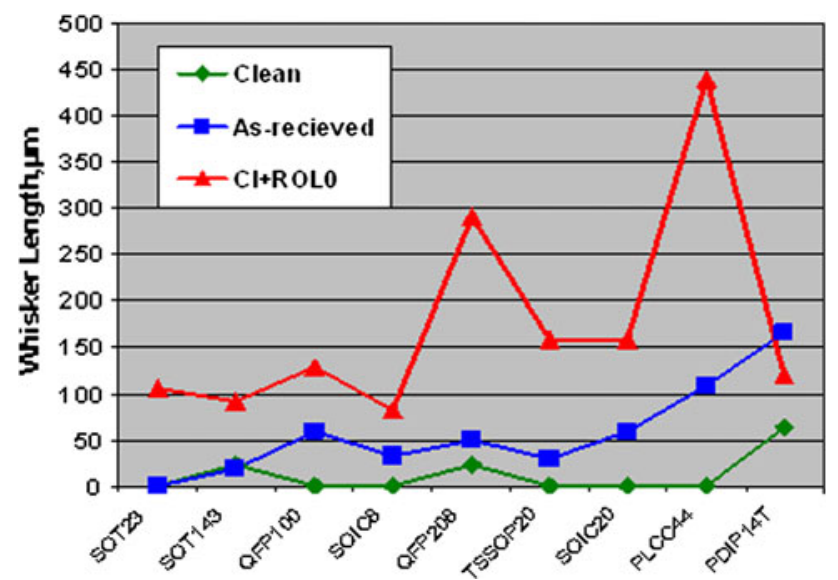

Fig. 11. Maximum whisker lengths after $1500 \mathrm{~h}$ at $85^{\circ} \mathrm{C} / 85 \% \mathrm{RH}$ depending on assembly cleanliness.

the components in production assemblies with long whiskers from prior work. ${ }^{6}$

SEM/EDX analysis revealed contamination locations and confirmed the presence of $\mathrm{Cl}, \mathrm{Br}, \mathrm{S}$, and $\mathrm{Na}$ (Fig. 5). The main areas of contaminant segregations were grain boundaries (Fig. 5a), gaps between leads and plastic body (Fig. 5b), surface roughness (Fig. 5c), and defects in plating such as open voids and cracks (Fig. 5d). These defects in Sn plating with exposed $\mathrm{Cu}$ are susceptible to galvanic corrosion. Defective Sn plating with voids and exposed $\mathrm{Cu}$ was detected on PIDIP14 and PLCC44.

\section{Results of Testing at $85^{\circ} \mathrm{C} / 85 \% \mathrm{RH}$}

\section{Testing for $500 \mathrm{~h}$}

There were no whiskers detected on the boards built using components cleaned prior to assembly and with a postassembly cleaning procedure typical for high-reliability products (Fig. 6a, b). Whiskers were detected in both as-received and contaminated assemblies (Fig. 6c-f). Figure 7 demonstrates the importance of cleanliness for whisker growth mitigation in soldered assemblies. Out of 13 components, 5 components as-received and 11 in purposely contaminated assemblies showed significant whisker growth. Table IV presents the relationship between the level of contamination of as-received components and whisker formation. If both individual species and total inorganic ions acceptance criteria were exceeded (bold values in Table IV), whiskers or hillocks grew. The longest whisker detected in as-received assemblies grew on PIDP14T and PLCC44. The whisker lengths were $280 \mu \mathrm{m}$ and $277 \mu \mathrm{m}$, respectively (Fig. 8). Whiskers were about five times longer in assemblies with additional contamination. The only exception was PDIP14T. The defects in Sn plating in this component were not repeatable from part to part. A trend of whisker length depending on component type was visible; QFP44, TSSOP20, SOIC20, and PLCC44 created longer whiskers than low-standoff SOT23 

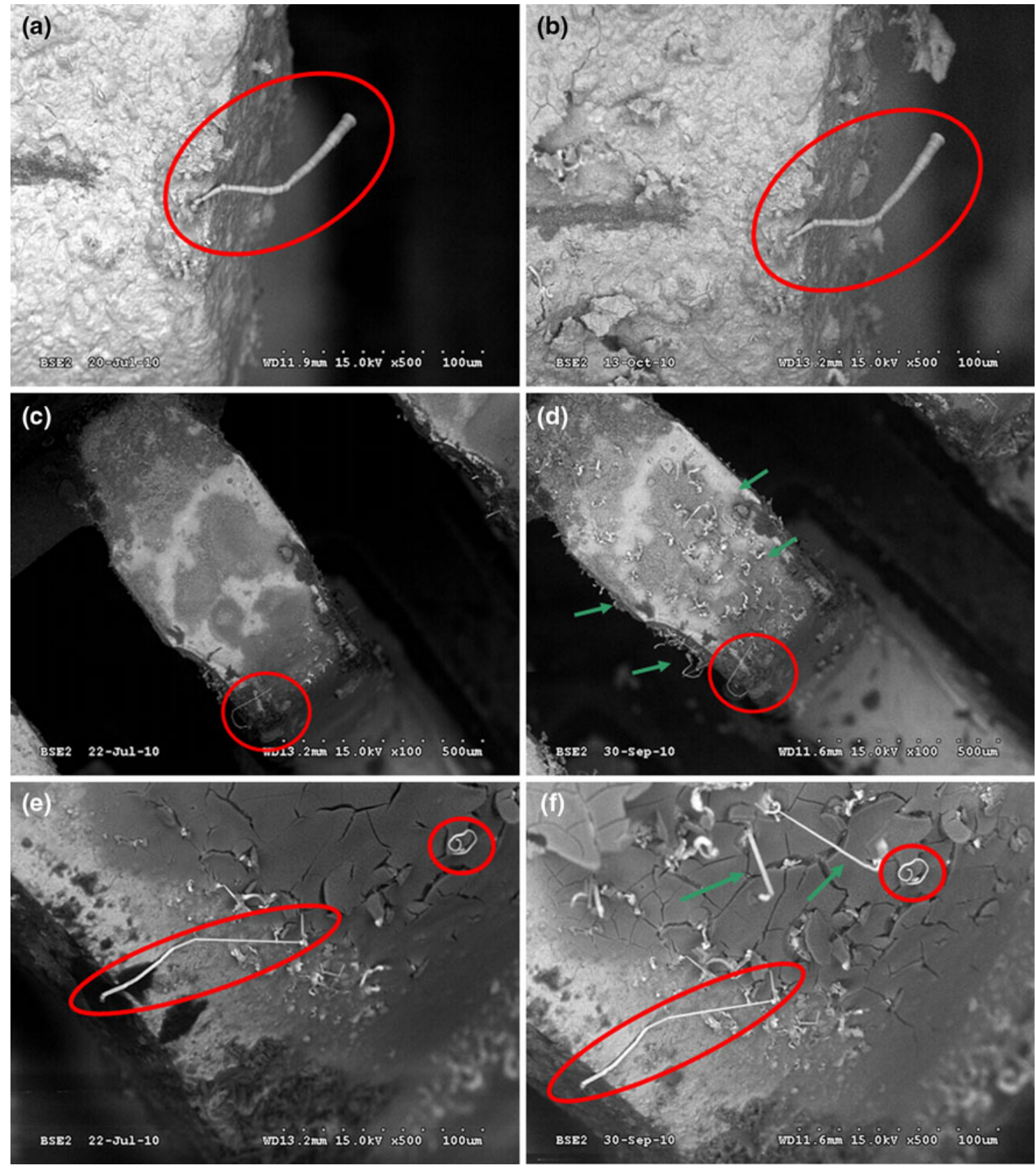

Fig. 12. Whisker images after $500 \mathrm{~h}(\mathrm{a}, \mathrm{c}, \mathrm{e})$ and $1500 \mathrm{~h}(\mathrm{~b}, \mathrm{~d}, \mathrm{f})$ at $85^{\circ} \mathrm{C} / 85 \% \mathrm{RH}$; circled whiskers appeared after $500 \mathrm{~h}$ and did not continue to grow after an additional $1000 \mathrm{~h}$; new whiskers formed during additional exposure are indicated by arrows.

and SOT143 and discretes. There was no significant difference between components with similar standoff for Alloy 42 (SOT23) and Cu-based alloy C7025 (SOT143) in terms of whisker formation.

Figure 9a allows us to separate the effect of component contamination and flux residues on whisker formation. Whiskers grow longer on intentionally contaminated components than on as-received components with a lower level of contamination in the assemblies without additional flux residue. Additional flux residue promotes whisker length up to $2.0 \times$. Only data on no-clean ROL0 fluxes are included in Fig. 9a.
There was no significant difference in whisker length depending on component contamination type. Figure $9 \mathrm{~b}$ demonstrates that $2 \mathrm{mM} \mathrm{NaCl}$ or $2 \mathrm{mM}$ $\mathrm{Na}_{2} \mathrm{SO}_{4}$ promoted whisker growth to approximately the same length in a no-clean solder process.

Compared with assembled components, loose parts had much lower propensity for whisker growth. Not only did clean loose components not form whiskers, but even contaminated components grew very short whiskers after $500 \mathrm{~h}$ at $85^{\circ} \mathrm{C} / 85 \%$ RH (Fig. 10). The longest whiskers were about $15 \mu \mathrm{m}$ to $17 \mu \mathrm{m}$ on components with $\mathrm{Cu}$ alloy leadframe materials and $23 \mu \mathrm{m}$ on components with 
(a)

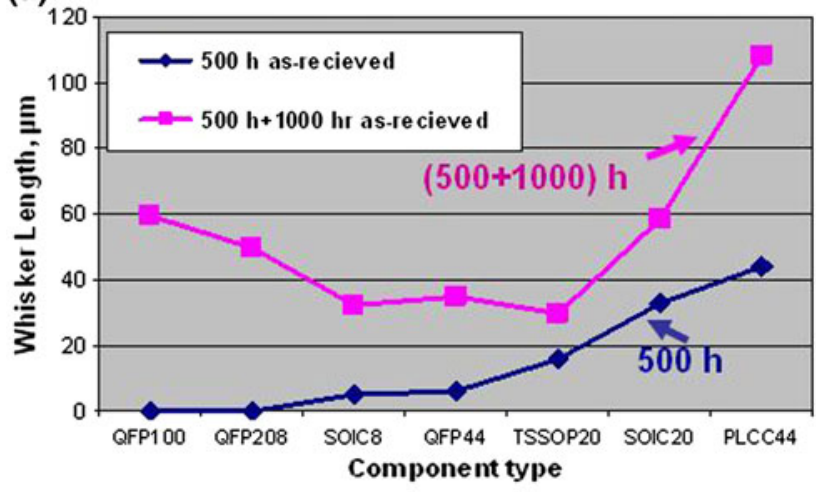

(b)

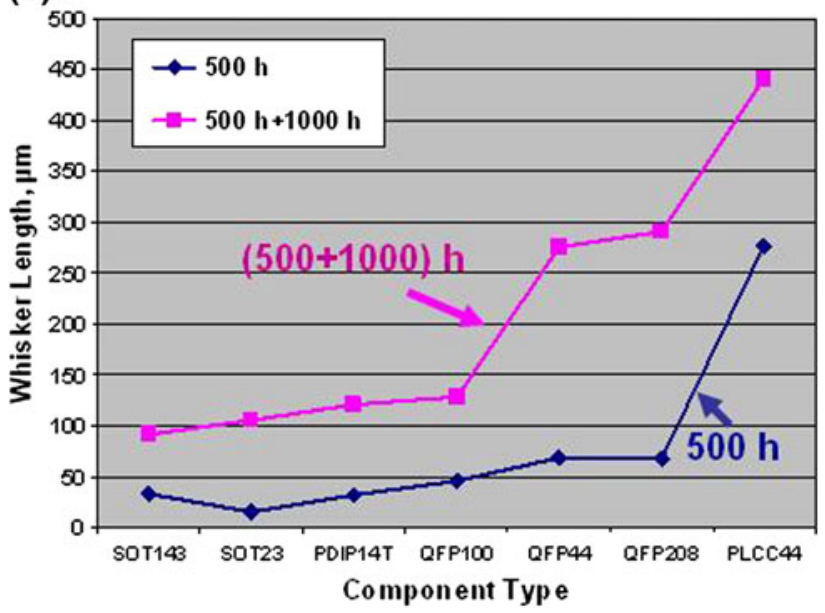

Fig. 13. Comparison of maximum whisker length after $500 \mathrm{~h}$ and after an additional $1000 \mathrm{~h}$ at $85^{\circ} \mathrm{C} / 85 \% \mathrm{RH}$ for: (a) as-received and (b) contaminated components in no-clean assemblies.

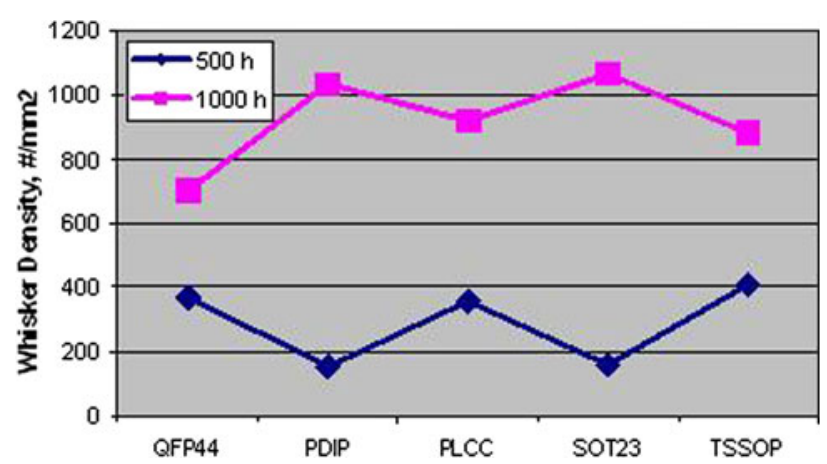

Fig. 14. Comparison of whisker density after $500 \mathrm{~h}$ and an additional $1000 \mathrm{~h}$ at $85^{\circ} \mathrm{C} / 85 \% \mathrm{RH}$.

Alloy 42. In the contaminated set of parts, 5 components out of 13 did not create whiskers, and hillocks shorter than $10 \mu \mathrm{m}$ were found on 2 contaminated components after $500 \mathrm{~h}$ at $85^{\circ} \mathrm{C} / 85 \%$ $\mathrm{RH}$. A comparison between whisker lengths of the loose and assembled components with the level of contamination is shown in Fig. 10. It is assumed that the soldering reduces propensity for whiskering of the Sn-plated components. For Sn-Pb assemblies,
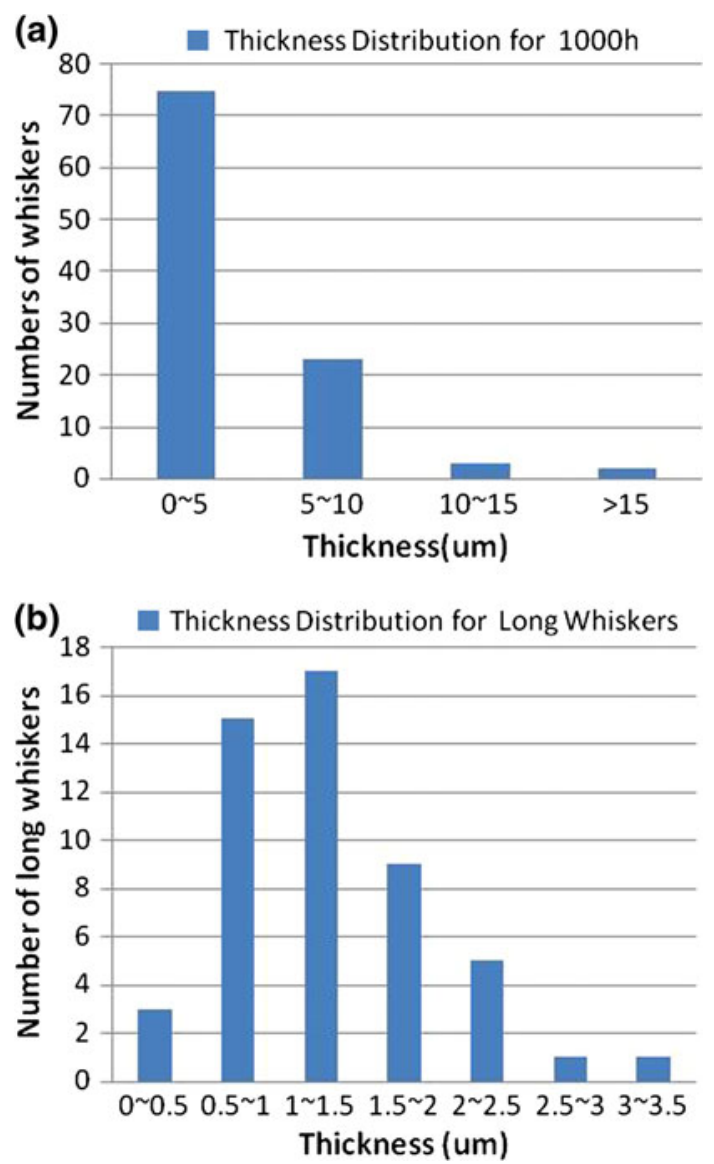

Fig. 15. Whisker thickness distribution.

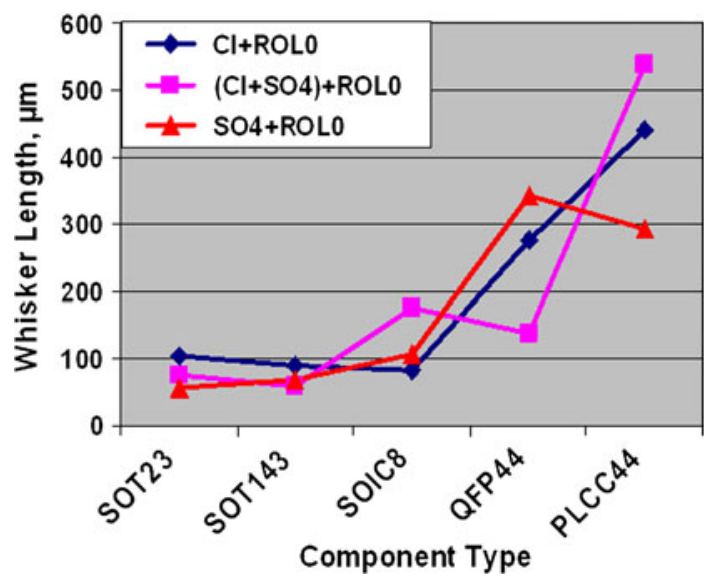

Fig. 16. Maximum whisker lengths after $1500 \mathrm{~h}$ at $85^{\circ} \mathrm{C} / 85 \% \mathrm{RH}$, showing no significant difference in whisker length depending on component contamination type.

it has been confirmed experimentally ${ }^{14}$ that fewer, shorter whiskers grew on assembled components than on loose ones in high-humidity conditions. This study showed that the situation is different for $\mathrm{Pb}$-free $\mathrm{Sn}-\mathrm{Ag}-\mathrm{Cu}$ solder alloys: SAC305 assemblies have higher propensity for whisker formation than loose components before soldering. Reflow using 
SAC305 solder does not mitigate whisker formation in a high-temperature/high-relative-humidity environment. There are several possible explanations for this phenomenon. First of all, SAC alloys do not contain $\mathrm{Pb}$, which is the strongest whisker mitigator. Contrarily to $\mathrm{Sn}-\mathrm{Pb}, \mathrm{SAC}$ alloys may have high ability to form whiskers because of microstructure characteristics that may trigger whisker formation in high-humidity environments (see "Microstructure and Whisker Formation in High-Humidity Environment").

\section{Testing for $1500 \mathrm{~h}$}

The next whisker inspection was done at $1000 \mathrm{~h}$ after the analyzed samples were placed into the chamber. The decision to increase the interval between inspections instead of using equal time periods as recommended by the JEDEC JESD22-A121A standard was based on a previous Celestica study. ${ }^{15}$ Huehne found that the longest whiskers he documented by measuring and taking photos after first $1000 \mathrm{~h}$, stop growing during the next $1000 \mathrm{~h}$ and further in the chamber. Instead, new whiskers appeared and kept growing approximately as long for the same exposure as the whiskers analyzed before.

Figure 11 shows a comparison of the longest whisker length between assemblies built using cleaned components and postassembly cleaning, assemblies with as-received components after a conventional no-clean assembly process, and assemblies with contaminated components and additional flux residue. Whiskers longer than $10 \mu \mathrm{m}$ and shorter than $40 \mu \mathrm{m}$ were detected in cleaned assemblies. Whiskers longer than $50 \mu \mathrm{m}(64.6 \mu \mathrm{m})$ were found only on highly defective PDIP14T joints. Longer whiskers were observed on assemblies with as-received components, and very long whiskers up to $450 \mu \mathrm{m}$ on PLCC and $300 \mu \mathrm{m}$ on QFP208 were found on assemblies with contaminated components and additional no-clean ROL0 flux residue.

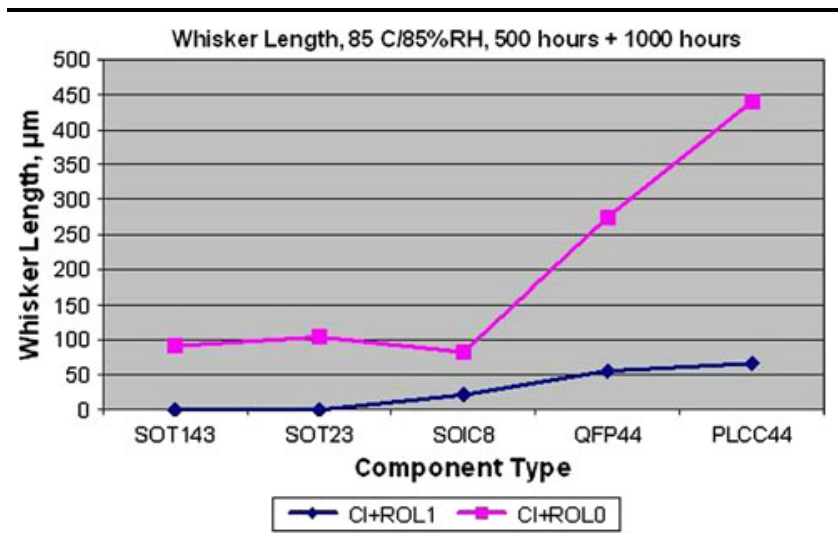

Fig. 17. Maximum whisker length after $1500 \mathrm{~h}$ at $85^{\circ} \mathrm{C} / 85 \% \mathrm{RH}$, showing longer whiskers in assemblies with no-clean ROLO resin flux residue compared with ROL1 rosin flux.
Detailed analysis showed that whiskers observed at $500 \mathrm{~h}$ did not grow further when examined at $1500 \mathrm{~h}(500+1000 \mathrm{~h})$. In Fig. 12 , whiskers that appeared at $500 \mathrm{~h}$ are circled in pictures taken after $500 \mathrm{~h}$ and after an additional $1000 \mathrm{~h}$. These whiskers do not continue growing if the samples are placed in the chamber again. New whiskers grow if the parts are reintroduced into a high-temperature/ high-humidity condition. These whiskers are indicated by arrows. Whisker length depends on time in the chamber without interruption (Fig. 13). This confirms the previous finding ${ }^{15}$ and allows us to conclude that periodic removal and inspection of whiskers will result in underreported whisker length as a function of time. The example of a whisker density increase with longer testing interval is shown in Fig. 14. To report a proper whisker dependence on high-temperature/high-humidity exposure time, one needs to increase the intervals between successive examinations.

There were still no whiskers found on loose clean components after the additional $1000 \mathrm{~h}$ in the chamber, whereas whiskers longer than $10 \mu \mathrm{m}$ and shorter than $40 \mu \mathrm{m}$ were detected in cleaned assemblies. The only exception was a loose PIDP14T growing a $20-\mu \mathrm{m}$-long whisker. After soldering, the whisker length on the PDIP14T joint was more than $3 \times$ longer, i.e., $64.4 \mu \mathrm{m}$. The same comparison is valid for all types of component and levels of contamination; the whiskers on loose components with $\mathrm{Cu}$ alloy leadframe were shorter than on assembled boards using SAC305 solder, confirming the statement that $\mathrm{Pb}$-free soldering does not mitigate whisker formation. Actually, SAC305 soldering promotes whiskering even if clean components are assembled on clean boards using the postassembly cleaning process; for instance, the longest whisker on a loose QFP44 contaminated with $\mathrm{Cl}$ after $1500 \mathrm{~h}$ at $85^{\circ} \mathrm{C} / 85 \% \mathrm{RH}$ was $23.6 \mu \mathrm{m}$. The same component assembled to PCB using the SAC305 no-clean process grew a $105-\mu \mathrm{m}$ whisker. Shorter whiskers after assembly than in the loose state were detected only on a SOT23 with Alloy 42 leadframe material.

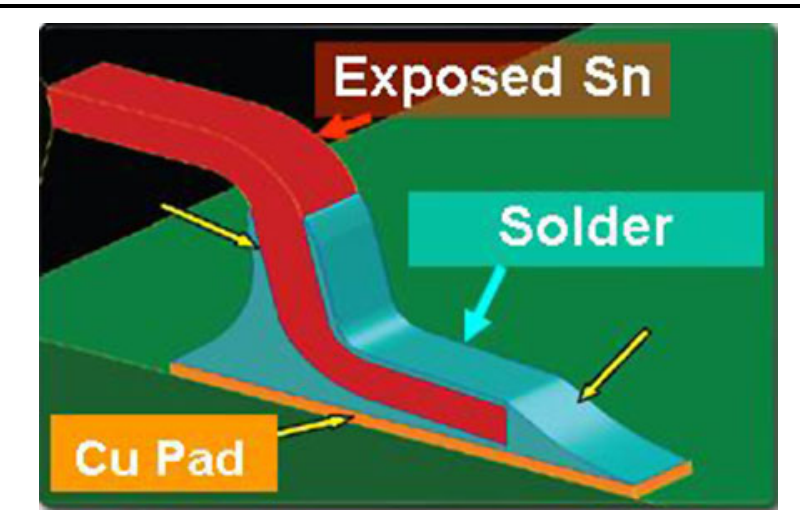

Fig. 18. Schematic of a typical solder joint of a leaded component. 

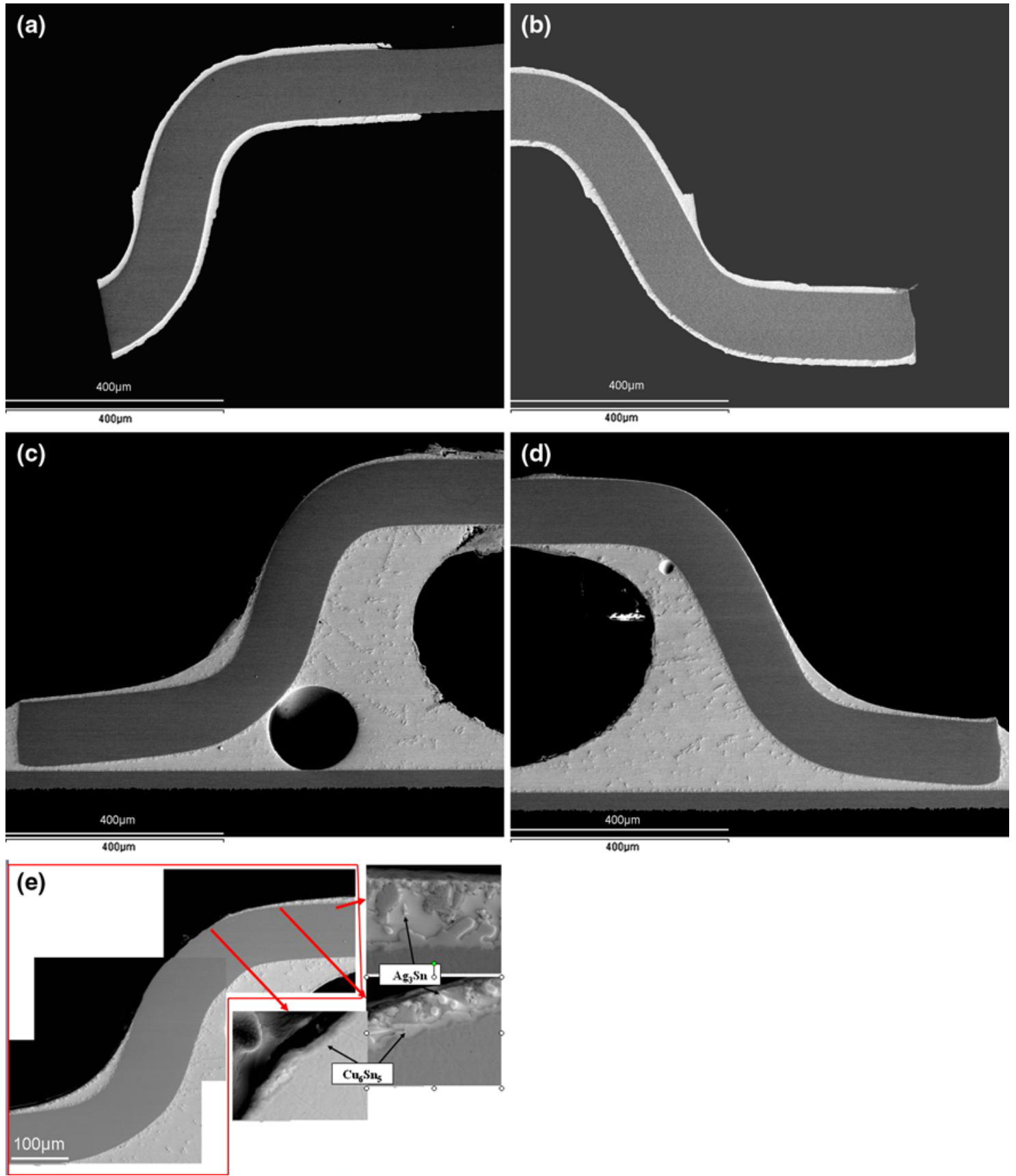

Fig. 19. TTSOP20 loose (a, b) and assembled (c-e) component tin or solder coverage after $500 \mathrm{~h}$ at $85^{\circ} \mathrm{C} / 85 \% \mathrm{RH}$, used as an example.

A typical example whisker thickness distribution is shown in Fig. 15. Of all whiskers, $75 \%$ are not thicker than $5 \mu \mathrm{m}$. Among long whiskers, the typical thickness is in the range from $0.5 \mu \mathrm{m}$ to $2.2 \mu \mathrm{m}$.

Similar to observations made after $500 \mathrm{~h}$, there was no dependence on component type in the influence of contamination on whisker length detected after the additional $1000 \mathrm{~h}$ at $85^{\circ} \mathrm{C} / 85 \%$ RH (Fig. 16). Surprisingly, no-clean ROL0 resin flux was found to promote whisker formation as compared with ROL1 rosin flux (Fig. 17). The trend for more whisker creation with no-clean assembly compared with cleaned units was observed by Oberndorff. ${ }^{14}$ He cited the observation made in Japan that abietic acid promotes corrosion. Abietic acid is a main constituency of ROL0 flux used in this study to imitate a rework/hand-soldering condition with not fully activated flux residue.

\section{Whisker Locations on Pb-Free Assembly}

A typical solder joint of a leaded component is shown in Fig. 18. Traditionally, two zones of this type of joint are distinguished: covered with solder and exposed $\mathrm{Sn}$. In $\mathrm{Sn}-\mathrm{Pb}$ solder joints, whiskers are 
associated with the exposed Sn zone. In this study, detailed analysis was performed on SAC305 solder joints. All 13 components were examined for solder coverage, "exposed Sn" microstructure, whisker locations, and the relationship of microstructure and whisker formation.

During component attachment to a printed circuit board (PCB) using SAC305 solder, solder melts and wets the leads. Electroplated $\mathrm{Sn}$ melts also because the SAC soldering reflow temperature is higher than $232^{\circ} \mathrm{C}$, which is above the $\mathrm{Sn}$ melting point $\left(223^{\circ} \mathrm{C}\right)$. The resulting joint in comparison with a loose component is shown in Fig. 19. The TTSOP20 loose and assembled components after $500 \mathrm{~h}$ at $85^{\circ} \mathrm{C} / 85 \% \mathrm{RH}$ are used as an example. The thickness of the electroplated Sn on the loose TTSOP20 is $12 \mu \mathrm{m}$ and is rather uniform across the lead (Fig. 19a). After reflow, the thickness of coverage varies significantly. The solder wicks up the lead, mixing with the molten Sn. Surface tension dictates the thickness of the coverage, which is thin at the convex knee area and thicker at concave regions. The very top of the lead coverage that is extended to the component body contains $\mathrm{Ag}_{3} \mathrm{Sn}$ particles (Fig. 19). The knee region is covered with an intermetallic layer about $2 \mu \mathrm{m}$ thick with no or small patches of Sn (Fig. 19). Although whiskers were found in all regions of solder joints, including the solder fillet on a toe area (Fig. 20a), the longest whiskers grow from the top and sides of lead hips and thighs (Fig. 20b-d).

Figure 21 shows typical locations of long whiskers on low- and high-standoff-height components, PTH, and discretes. As a rule, the thickness of coverage in these locations is minimal and varies from $2.4 \mu \mathrm{m}$ to $11.6 \mu \mathrm{m}$. In most joints, excluding only PDIP14T, the coverage contains some $\mathrm{Ag}_{3} \mathrm{Sn}$ particles in the grain boundaries (Fig. 22). The presence of the $\mathrm{Ag}_{3} \mathrm{Sn}$ particles confirms that the $\mathrm{Sn}$ was melted and interacted with the SAC305 solder. The fraction of the particles varies significantly for different components and locations. Whiskers grow from the Sn grains surrounded by $\mathrm{Ag}_{3} \mathrm{Sn}$ network, as shown in Fig. 22.

The longest whiskers on PDIP14T were formed at the thigh-knee interface where the coverage looked like unmelted electroplated Sn (Fig. 22). Because this component was attached to the PCB manually after reflow, it is possible that the top part of leads in contact with the component body did not reach the Sn melting temperature $\left(232^{\circ} \mathrm{C}\right)$. The intermetallic thickness in this layer was $1.0 \mu \mathrm{m}$, which was about 2 to 3 times thinner than in the rest of the components with $\mathrm{Cu}$ alloy leadframes.
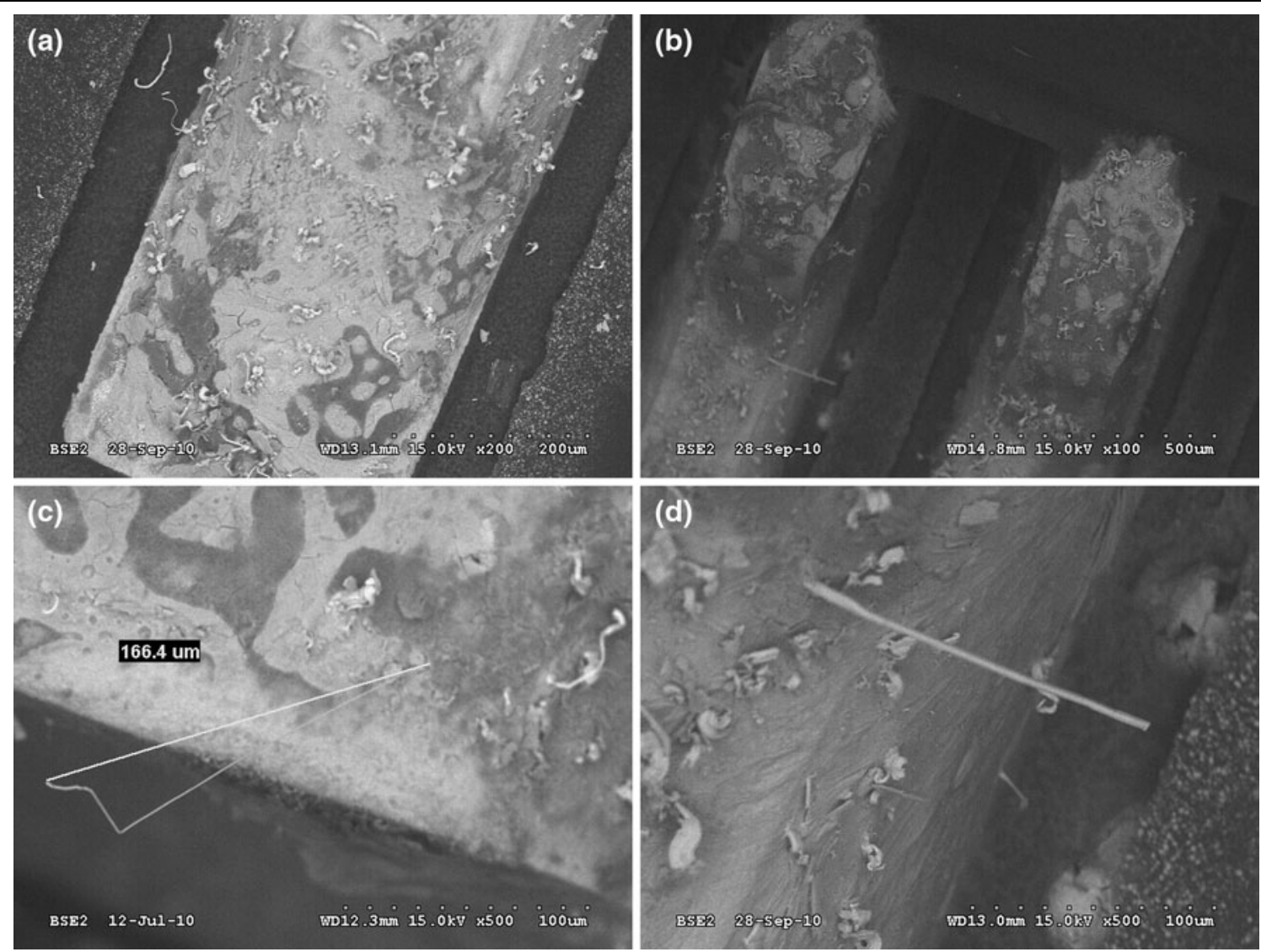

Fig. 20. TTSOP20 images illustrating whisker growth from solder fillet on toe area (a) and from the top and sides of leads (b-d). 

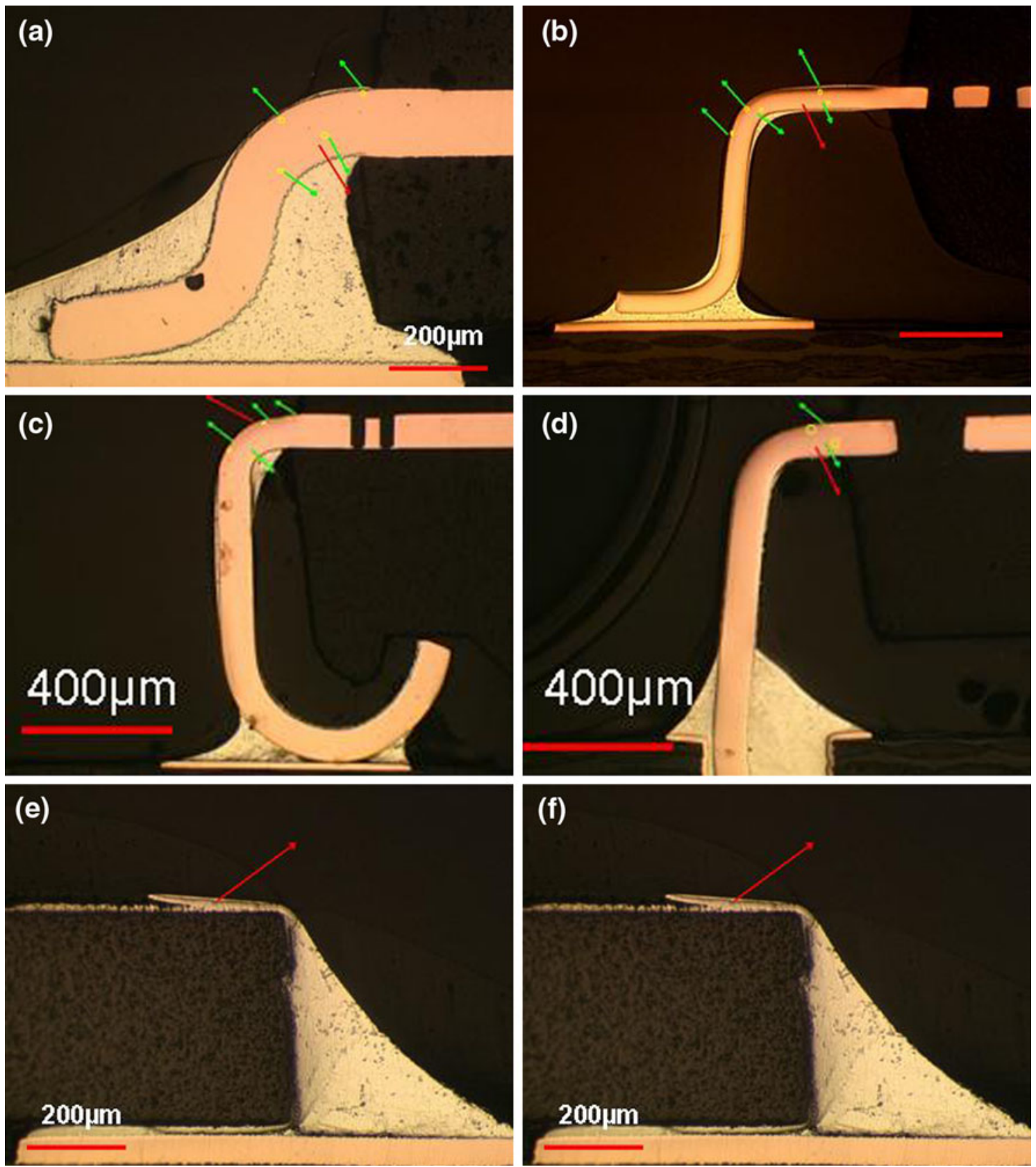

Fig. 21. Typical locations of long whiskers on low- and high-standoff-height components, PTH, and discretes; red arrows-longest whiskers, green arrows-shorter whiskers, yellow circles-hillocks.

\section{Microstructure and Whisker Formation in High-Humidity Environment}

\section{Oxidation and Corrosion}

In all of the cases where whiskers were found, oxidation or corrosion was present as well. Humidity has been proven to cause extreme growth of whiskers. ${ }^{14}$ This study has shown that condensation is not a necessary prerequisite for corrosion to happen. In this study, all precautions were taken to prevent condensation. Detailed inspection showed no condensation spots after exposure. It is believed that $\mathrm{Sn}$ reacts with $\mathrm{O}$ to form dioxide $\left(\mathrm{SnO}_{2}\right)$, oxide
( $\mathrm{SnO})$, and hydrated dioxide $\left(\mathrm{SnO}_{2}\right.$-hydrated). The formation of $\mathrm{Sn}$ oxides results in volume expansion of about $29 \%$ to $34 \% .^{16}$ This expansion results in compressive stress, causing Sn whisker growth to release this stress.

Oxidation of loose components and components soldered to the PCB occurs by different mechanisms. Corrosion on loose components was observed first near exposed base material on the toe area and close to the component body, or on areas around defects in Sn plating with exposed $\mathrm{Cu}$. The exposed $\mathrm{Cu}$ that is present immediately adjacent to the $\mathrm{Sn}$ causes galvanic corrosion. Ionic contamination 

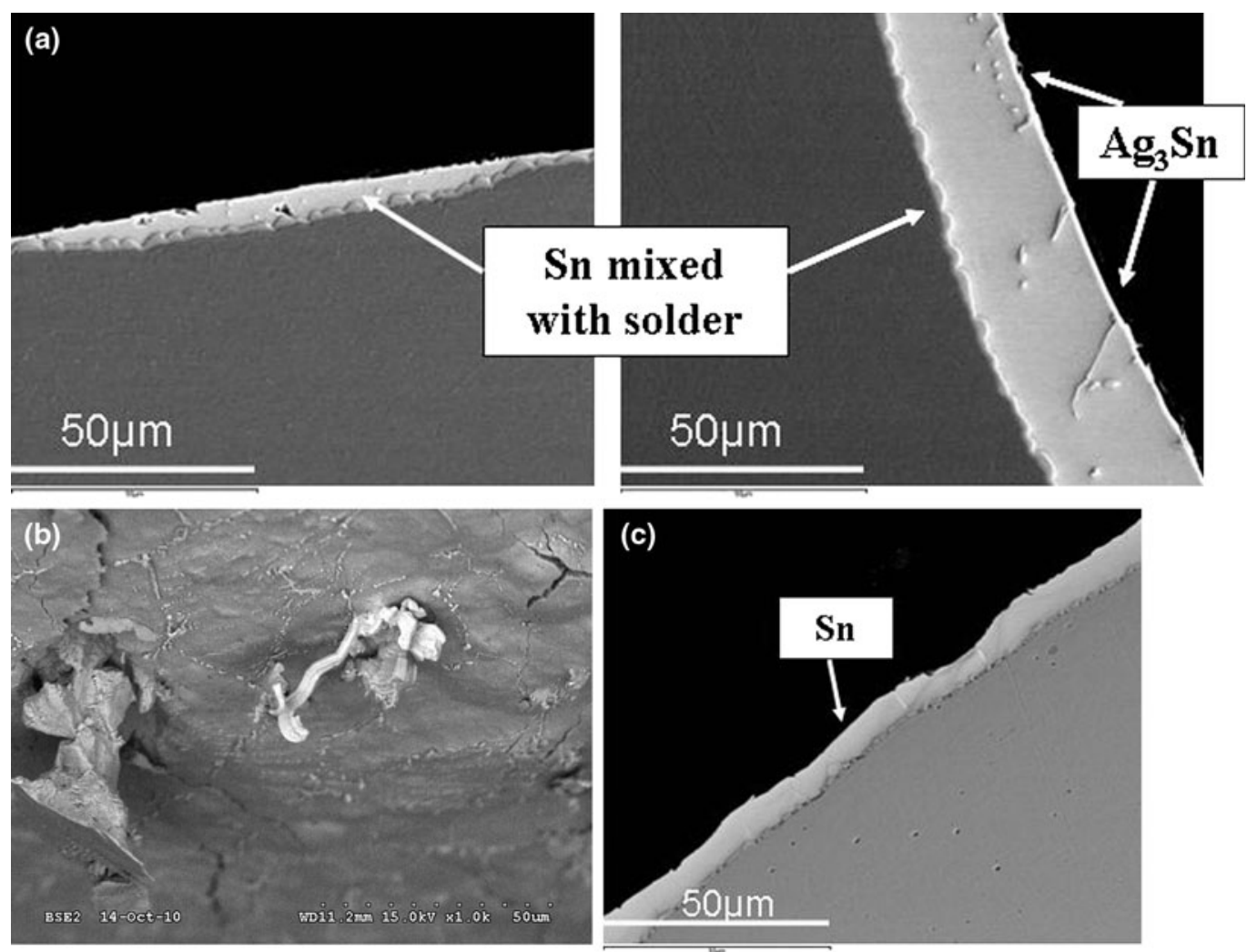

Fig. 22. Coverage of leads in solder joints containing some $\mathrm{Ag}_{3} \mathrm{Sn}$ particles in the grain boundaries (a, b) and pure $\mathrm{Sn}(\mathrm{c})$; the presence of the $\mathrm{Ag}_{3} \mathrm{Sn}$ particles confirms that the Sn was melted and interacted with the SAC305 solder.
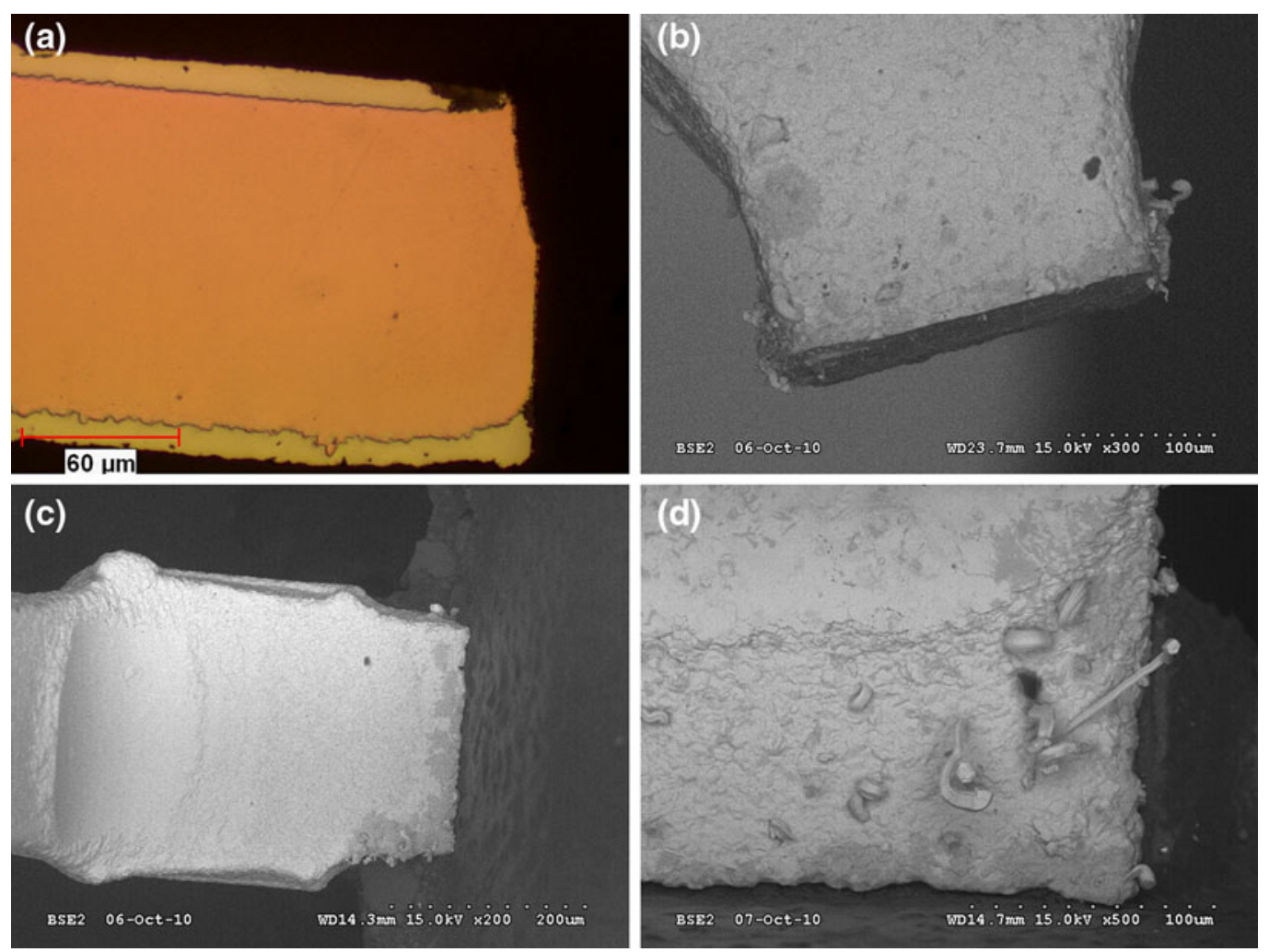

Fig. 23. Micrographs of loose contaminated components showing corrosion and whiskers in toe regions (a, b) and close to the board connection (c, d) after $1500 \mathrm{~h}$ at $85^{\circ} \mathrm{C} / 85 \% \mathrm{RH}$. 

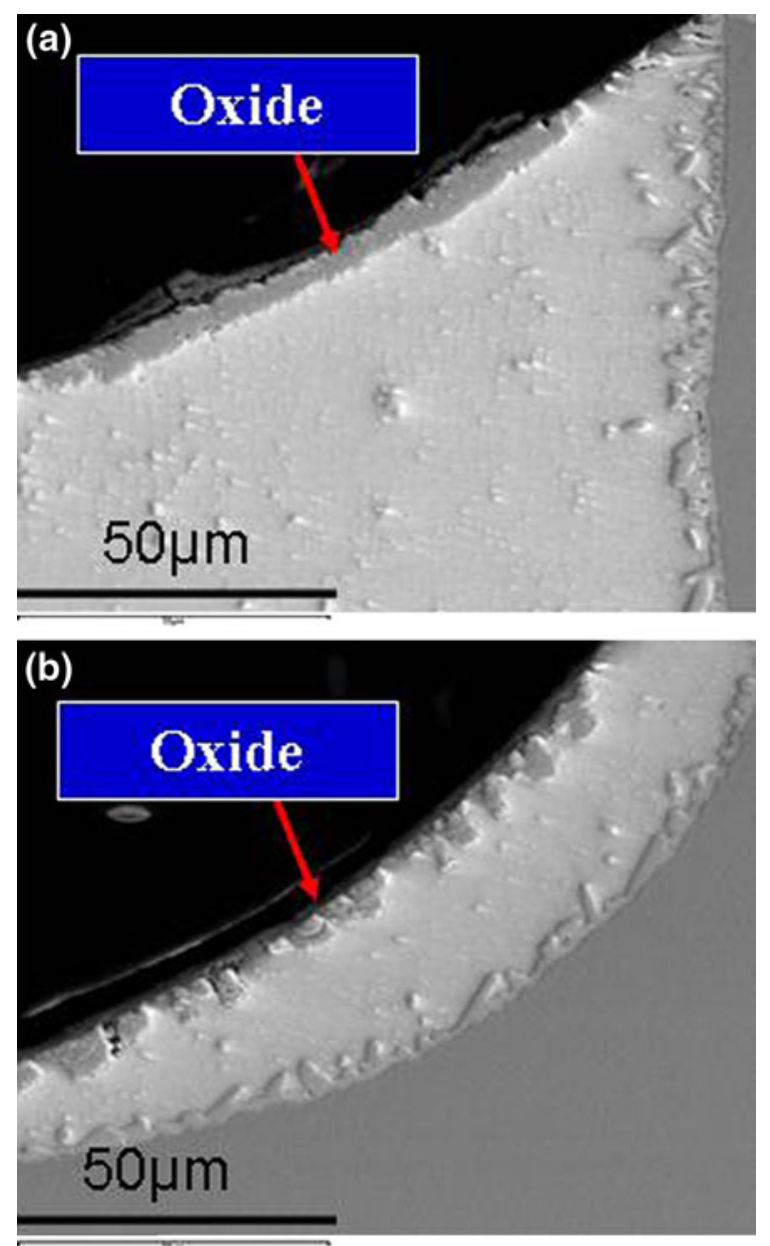

Fig. 24. Cross-sections of solder joints exposed to high-temperature/high-humidity conditions with uniform oxide layer (a) and oxidation penetrating along the grain boundaries to form patches (b).

accelerates corrosion. Clean loose components do not demonstrate corrosion and do not grow whiskers after $1500 \mathrm{~h}$ at $85^{\circ} \mathrm{C} / 85 \% \mathrm{RH}$. The exception is PDIP14T, with many open voids in the Sn plating with exposed $\mathrm{Cu}$. In contaminated components, corrosion and whiskers appeared in the toe regions and close to the board connection (Fig. 23).

The observations made in the current study on solder joints showed that, depending on the microstructure of the Sn-based alloy, the oxide layer may look uniform or penetrate along the grain boundaries and form patches (Fig. 24). These patches may penetrate to the leadframe material, propagate along the interface with solder, and isolate the Sn grains from the rest of the solder. These islands of Sn surrounded by Sn oxide mostly created whiskers (Fig. 25).

The at.\% ratio of the EDX analysis perfectly matched with the $\mathrm{SnO}_{2}$ oxide formula (Fig. 26), which corresponds to the data,${ }^{17}$ indicating that, in tin oxide films thicker than $50 \mathrm{~nm}$, Sn is completely oxidized to $\mathrm{SnO}_{2}$. The $\mathrm{SnO}_{2}$ is mainly present as polycrystalline particles with average size of about $5 \mathrm{~nm}$.
As shown above, in $\mathrm{Pb}$-free assemblies using SAC solder alloys, in most cases the component leads are covered with a mixture of Sn finish and solder. The microstructure of these layers consists of Sn grains with $\mathrm{Ag}_{3} \mathrm{Sn}$ network around the grains.

\section{Role of $\mathrm{Ag}_{3} \mathrm{Sn}$}

Figure 27 shows SOT23 and TSSOP20 solder joints on a clean SAC305 assembly after $1500 \mathrm{~h}$ at $85^{\circ} \mathrm{C} / 85 \% \mathrm{RH} . \mathrm{Ag}_{3} \mathrm{Sn}$ primary particles on the surface of solder are surrounded by an oxidized zone perfectly shaped as an oval around the $\mathrm{Ag}_{3} \mathrm{Sn}$ plates. Deterioration of solder propagates from the $\mathrm{Ag}_{3} \mathrm{Sn} / \mathrm{Sn}$ boundary outward. This may be caused by the difference in the $\mathrm{Ag}_{3} \mathrm{Sn}$ and $\mathrm{Sn}$ galvanic potentials. Song and Ricky Lee ${ }^{18}$ showed that the potential of $\mathrm{Ag}_{3} \mathrm{Sn}$ is nearly the same as that of pure $\mathrm{Ag}$. Presence of $\mathrm{Ag}_{3} \mathrm{Sn}$ may accelerate dissolution of $\mathrm{Sn}$ due to galvanic corrosion. Compared with the $\mathrm{Ag}_{3} \mathrm{Sn}$ phase, $\beta$-Sn is more active and easily becomes eroded in the corrosive conditions that exist on the surface of solder in a high-humidity environment. An oxide layer forms on the surface and grows inside the solder along the grain boundaries. Oxidation propagates also through the interdendritic arrangement of eutectic $\mathrm{Ag}_{3} \mathrm{Sn}$ particles. The leadframe material does affect the oxidation in this case. There is no difference in oxidation appearance between SOT23 with Alloy 42 lead base material and TSSOP20 with $\mathrm{Cu}$ alloy $\mathrm{C} 7025$.

Whiskers grow inside the zone affected by oxidation. In Fig. 28 the TSSOP20 with several zones of oxidation around $\mathrm{Ag}_{3} \mathrm{Sn}$ plates on bulk solder and on a lead covered with solder are shown. Both recrystallized grains and whiskers are clearly visible.

\section{Contamination and Surface Roughness}

Corrosion and whisker formation are accelerated if ionic contamination is present. The solder oxidation first affects the locations with $\mathrm{Ag}_{3} \mathrm{Sn}$ particles. The eutectic $\mathrm{Ag}_{3} \mathrm{Sn}$ particles solidify from the last portion of liquid occupying the Sn interdendritic spaces and surrounding the Sn dendrite arms (Fig. 29a). The contaminants from contaminated components and solder paste tend to segregate in the same areas as well. In addition, the difference between liquid and solid eutectic volumes creates grooves in interdendritic spaces, also known as shrinkage voids (Fig. 29a, b). Contamination from flux may be trapped in these shrinkage voids during assembly. Long, narrow shrinkage grooves make it difficult to carry out proper cleaning. Also, unreacted flux residues readily absorb moisture, which promotes the formation of corrosion.

Therefore, oxidation and corrosion of both bulk solder and the mixture of the Sn finish and solder on the component leads are significantly accelerated in the presence of ionic contamination. Figure 29c-e shows corrosion products in the interdendritic 

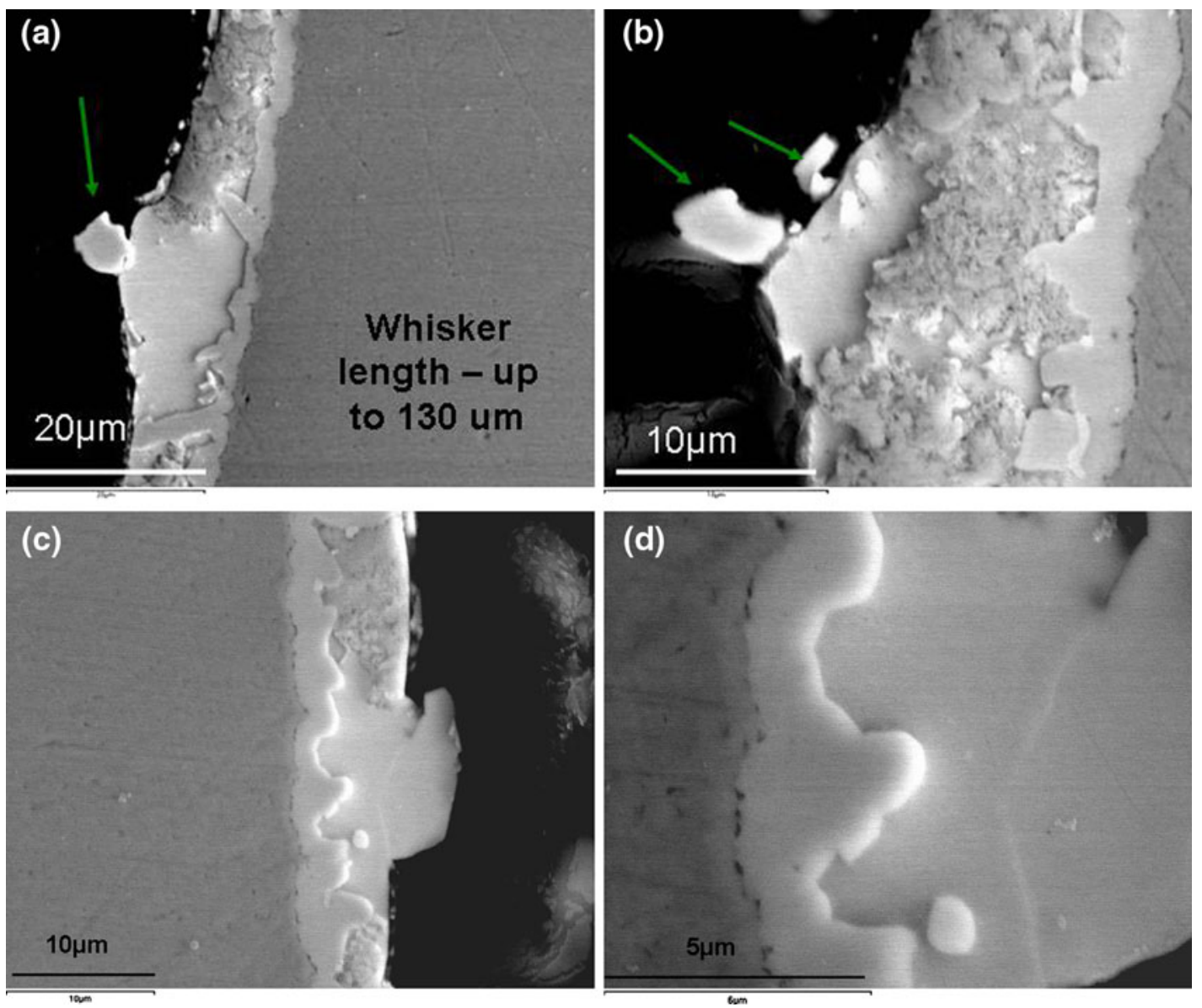

Fig. 25. Cross-sections of solder joints exposed to high-temperature/high-humidity conditions with solder surrounded by oxide patches that created long whiskers: (a, c) oxide layer from sides; (b) oxide patches penetrated to the leadframe material, and propagated along the interface with solder, isolating the Sn grains; (d) details of image (c) showing a horizontal grain boundary between solder and whisker.

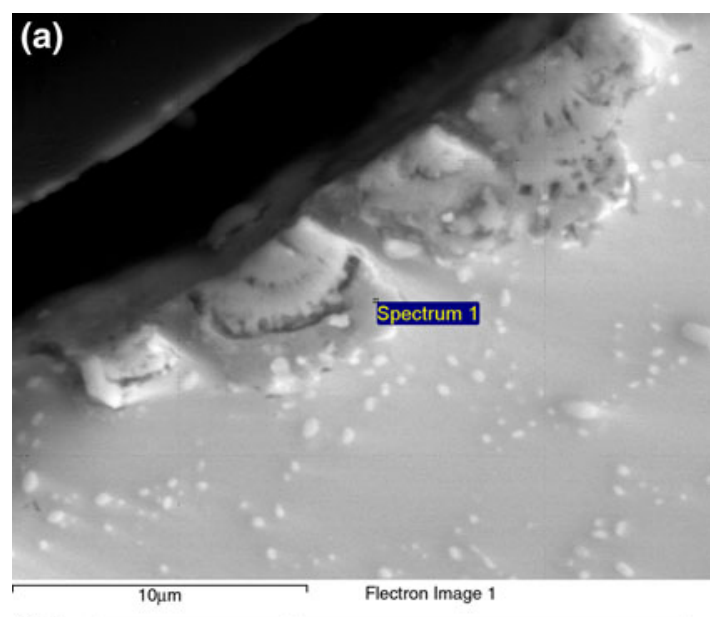

(b)

\begin{tabular}{l|ll}
\hline Element & Weight\% & Atomic\% \\
O K & 19.2 & 63.2 \\
Cu K & 1.7 & 1.4 \\
Ag L & 4.0 & 2.0 \\
Sn L & 75.1 & 33.4 \\
Totals & 100.00 & \\
\hline
\end{tabular}

Fig. 26. SEM image and EDX analysis of Sn oxide. location in the sample with Cl-contaminated component and residue of diluted ORH1 flux after $500 \mathrm{~h}$ at $85^{\circ} \mathrm{C} / 85 \% \mathrm{RH}$. The corrosion product contains the eutectic constituents $(\mathrm{Sn}, \mathrm{Ag}$, and $\mathrm{Cu}$ ) as well as oxygen and about 11 at.\% Cl. Tin oxychlorides were detected at the surface of all the SAC alloys investigated after electrochemical tests in Ref. 19 and may be formed in this case as well.

\section{CONCLUSIONS Cleanliness Consideration}

Based on analysis after $500 \mathrm{~h}$ and $1500 \mathrm{~h}$ exposure in an $85^{\circ} \mathrm{C} / 85 \% \mathrm{RH}$ environment, the following conclusions can be made. Use of clean components and boards and postassembly cleaning significantly reduces the propensity for whisker formation in $\mathrm{Pb}$-free products. As-received parts in no-clean assemblies may grow whiskers in a relatively short time. Ionic contamination species such as $\mathrm{Cl}^{-}, \mathrm{SO}_{4}^{2-}$, $\mathrm{NO}^{3-}$, and $\mathrm{Br}^{-}$are main triggers for whisker formation. Flux residue significantly increases the propensity for whisker growth. Contaminated components create very long whiskers in a short time if flux residue is present. 

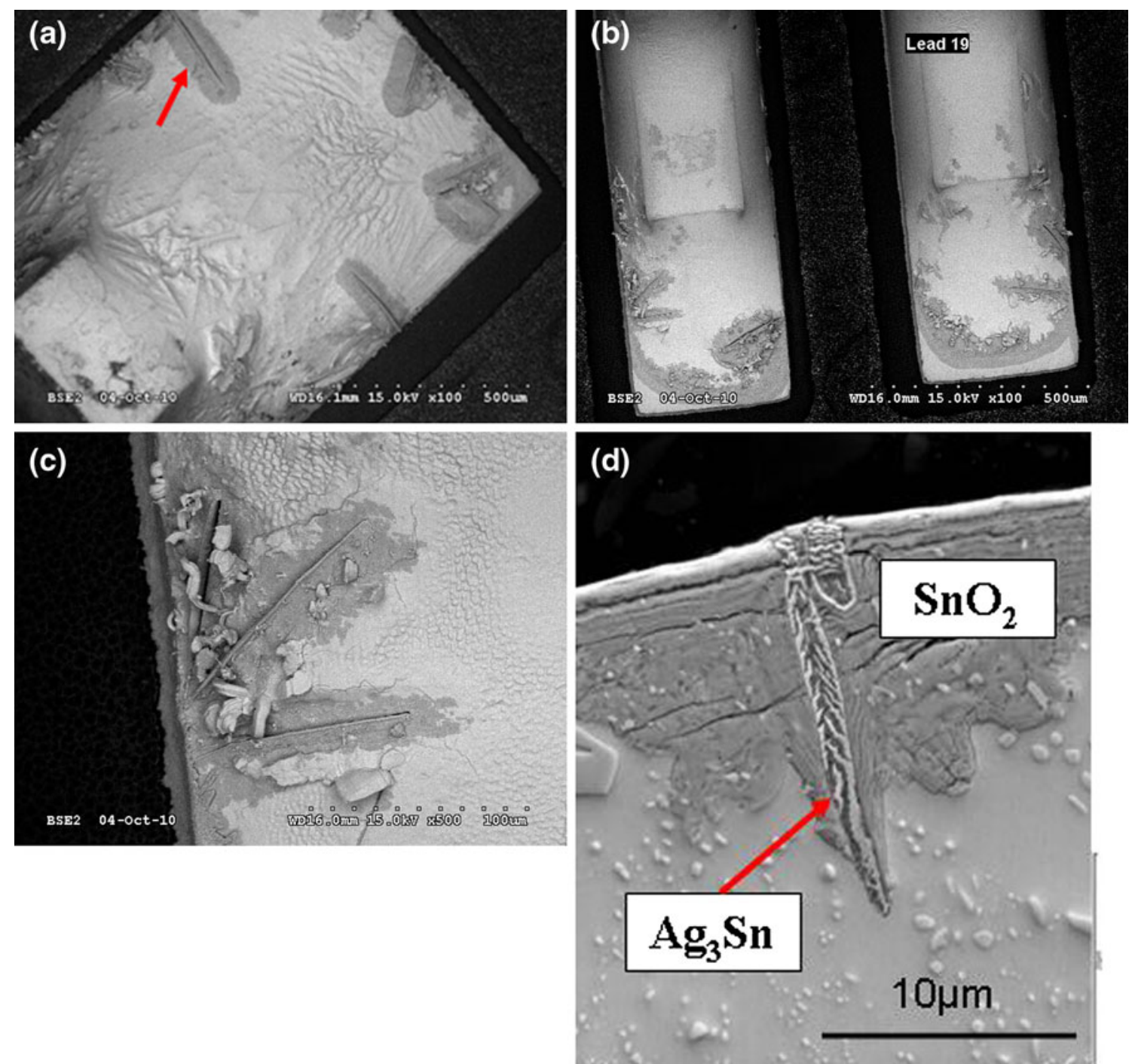

Fig. 27. SOT23 (a) and TSSOP20 (b, c) top view and cross-section (d) of solder joints on a clean SAC305 assembly after $1500 \mathrm{~h}$ at $85^{\circ} \mathrm{C} / 85^{\circ}$ $\mathrm{RH} ; \mathrm{Ag}_{3} \mathrm{Sn}$ primary particles on the surface of solder are surrounded by an oxidized zone perfectly shaped as an oval around the $\mathrm{Ag}_{3} \mathrm{Sn}$ plates.

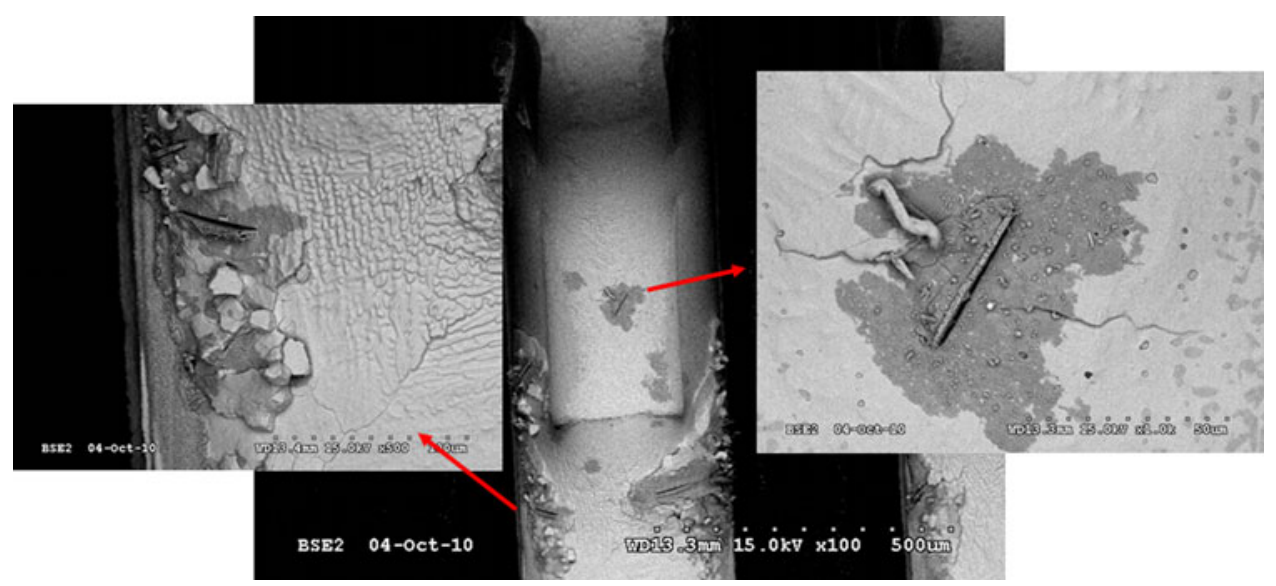

Fig. 28. TSSOP20 with several zones of oxidation around $\mathrm{Ag}_{3} \mathrm{Sn}$ plates on bulk solder and on lead covered with solder; recrystallized grains and whiskers inside the zone affected with oxidation. 

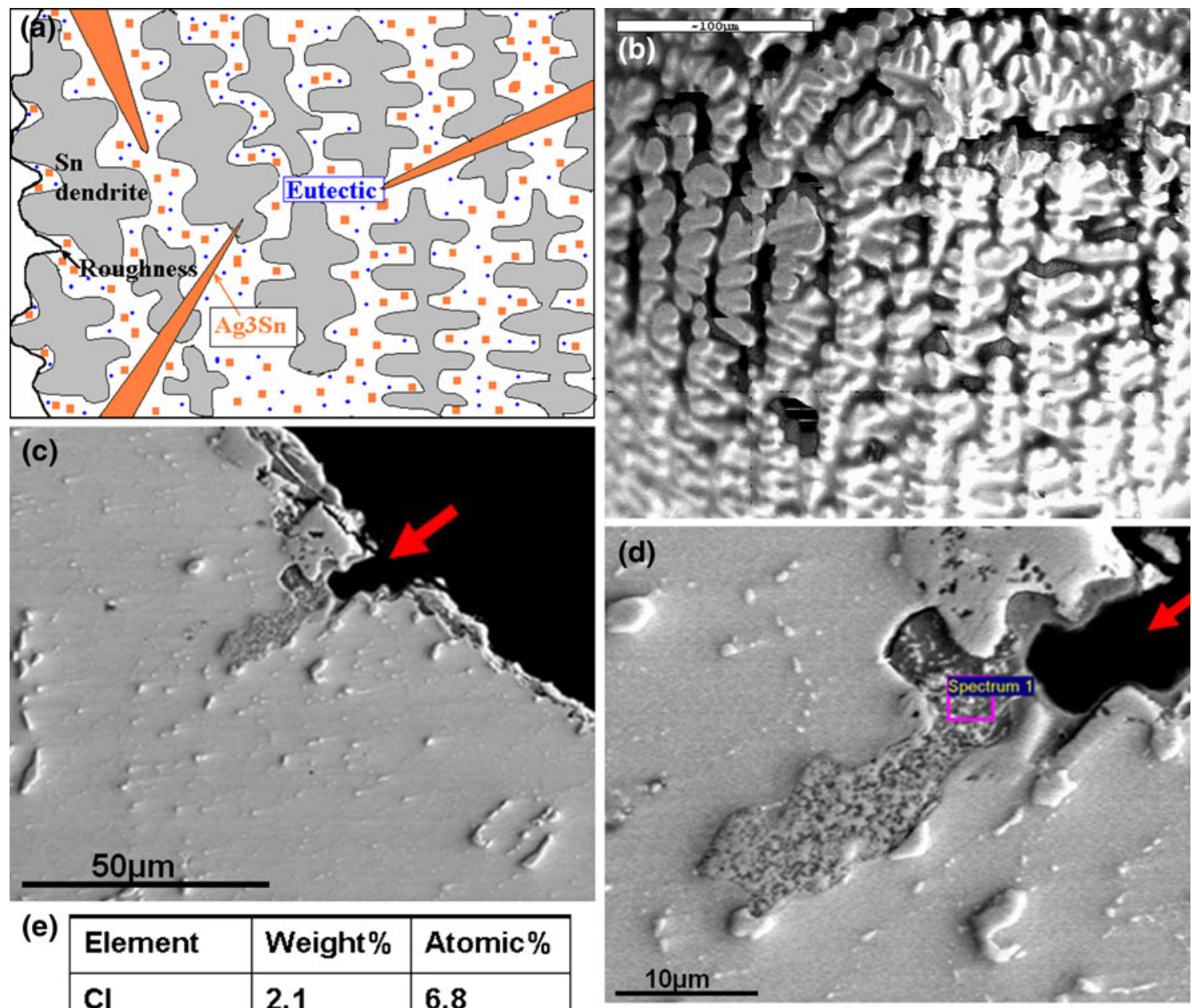

(e)

\begin{tabular}{|l|l|l|}
\hline Element & Weight $\%$ & Atomic \% \\
\hline $\mathrm{Cl}$ & 2.1 & 6.8 \\
\hline Sn & 97.9 & 93.2 \\
\hline Totals & 100.00 & \\
\hline
\end{tabular}

Fig. 29. Schematic of solder microstructure (a), top view of solder joint with shrinkage (b), and corrosion products in the interdendritic location in the sample with $\mathrm{Cl}$-contaminated component and residue of diluted $\mathrm{ORH} 1$ flux after $500 \mathrm{~h}$ at $85{ }^{\circ} \mathrm{C} / 85 \% \mathrm{RH}(\mathrm{c}-\mathrm{e})$.

\section{Testing Consideration}

Periodic removal and inspection of whiskers will result in underreported whisker length as a function of time; to report a proper length-time dependency, the interval between successive examinations needs to be increased.

\section{Microstructure Consideration}

Reflow using SAC305 solder does not mitigate whisker formation in high-T/high-RH environments. Preferential oxidation of Sn around primary and eutectic $\mathrm{Ag}_{3} \mathrm{Sn}$ in high humidity may promote whisker growth due to an increase in stress. Solder roughness exaggerates whisker formation because of contamination entrapment.

\section{General Conclusions}

Whisker formation is a manufacturing concern; it is not only a supply-chain issue. Not all of the critical control parameters are known. Plating quality and ionic cleanliness requirements for both suppliers and manufacturers have not yet been formulated. Assembly materials and their interaction and process parameters must be carefully considered. Whisker testing should be included in product qualification for high-reliability applications. Testing requirements and methods should be carefully considered.

\section{ACKNOWLEDGEMENTS}

The authors thank the following individuals from Celestica: Heather McCormick for assembly, and Pooneh Vaziri, Andrea Rawana, and Prakash Kapadia for ion chromatography analysis.

\section{OPEN ACCESS}

This article is distributed under the terms of the Creative Commons Attribution Noncommercial License which permits any noncommercial use, 
distribution, and reproduction in any medium, provided the original author(s) and source are credited.

\section{REFERENCES}

1. G.T. Galyon, IEEE Trans. Packag. Manuf. 28, 94 (2005).

2. M. Dittes, P. Oberndorff, and L. Petit, Proceedings of Electronic Components and Technology Conference (New Orleans, LA, 2003), p. 822.

3. R. Schetty, IEEE International Conference on the Business of Electronic Product Reliability and Liability (2004).

4. M. Dittes, P. Oberndorff, P. Crema, and V. Schroeder, Proceedings of Electronic Packaging Technology Conference (Singapore, 2003), p. 183.

5. J.W. Osenbach, R.L. Shook, B.T. Vaccaro, B.D. Potteiger, A.N. Amin, K.N. Hooghan, P. Suratkar, and P. Ruengsinsub, IEEE Trans. Packag. Manuf. 28, 36 (2005).

6. P. Snugovsky, Z. Bagheri, M. Romansky, SMTA Conference (2008).

7. D. Hillman, IPC/SMTA Cleaning \& Conformal Coating Conference (2010).

8. T. Tsukui, 2nd International Symposium on Whisker Growth (2008).

9. A. Baated, K.S. Kim, K. Suganuma, S. Huang, B. Jurcik, S. Nozawa, and M. Ueshima, J. Mater. Sci. 21, 1066 (2010).
10. K. Sweatman, J. Masuda, T. Nozu, M. Koshi, and T. Nishimura, Proceedings of IPC Printed Circuits Expo, APEX Conference (Los Vegas, 2009).

11. O. Kurtz, J. Barthelmes, and K. Martin, Proceedings of the SMTA International Conference (2008).

12. J. Arnold, G. Caswell, C. Hillman, and S. Binfield, WWW.dfrsolutions.com/.../HowDfRCanHelpYouControlIonic Contami. White. Paper How DfR Can Help You Control Ionic Contamination.

13. M. Ueshima, 3rd International Symposium on Tin Whiskers (2009).

14. P. Oberndorff, M. Dittes, P. Crema, P. Su, and E. Yu, IEEE Trans. Electron. Packag. Manuf. 29, 4 (2006).

15. M. Huehne, 4th International Symposium on Tin Whiskers (2010).

16. A. Baated, K. S. Kim, K. Suganuma. S. Huang. B. Jurcik, S. Nozawa, B. Stone, and M. Ueshima, Proceedings of SMTA International Conference (2009).

17. H. Sosiati, S. Hata, N. Kuwano, Y. Iwane, Y. Morizono, and Y. Ohno, Microstructural Characterization of Whiskers and Oxidized Surfaceon $\mathrm{Sn} / \mathrm{FeNi42}$ and $\mathrm{Pb}$-free Alloys, Proceedings CARTS Europe 2006 (Bad Homburg, Germany, 2006), pp. 263-269.

18. F. Song and S.W. Ricky Lee, IEEE, Electronic Components and Technology Conference (2006).

19. F. Rosalbino, E. Angelini, G. Zanicchi, R. Carlini, and R. Marazza, Electrochim. Acta 54, 7231 (2009). 